\title{
Monstrous Remediation
}

by

Tim Rosenberg B.A.S.

A thesis submitted to

the Faculty of Graduate Studies

in partial fulfillment of

the requirements for the degree of

\section{MASTER OF ARCHITECTURE}

M.Arch. (Professional)

Carleton University

OTTAWA, Ontario

May $7^{\text {th }}, 2007$

C 2007, Tim Rosenberg 


$\begin{array}{ll}\begin{array}{l}\text { Library and } \\ \text { Archives Canada }\end{array} & \begin{array}{l}\text { Bibliothèque et } \\ \text { Archives Canada }\end{array} \\ \begin{array}{l}\text { Published Heritage } \\ \text { Branch }\end{array} & \begin{array}{l}\text { Direction du } \\ \text { Patrimoine de l'édition }\end{array} \\ \begin{array}{l}\text { 395 Wellington Street } \\ \text { Ottawa ON K1A ON4 }\end{array} & \begin{array}{l}\text { 395, rue Wellington } \\ \text { Ottawa ON K1A ON4 } \\ \text { Canada }\end{array}\end{array}$

Your file Votre référence ISBN: 978-0-494-26977-0 Our file Notre référence ISBN: 978-0-494-26977-0

NOTICE:

The author has granted a nonexclusive license allowing Library and Archives Canada to reproduce, publish, archive, preserve, conserve, communicate to the public by telecommunication or on the Internet, loan, distribute and sell theses worldwide, for commercial or noncommercial purposes, in microform, paper, electronic and/or any other formats.

The author retains copyright ownership and moral rights in this thesis. Neither the thesis nor substantial extracts from it may be printed or otherwise reproduced without the author's permission.
AVIS:

L'auteur a accordé une licence non exclusive permettant à la Bibliothèque et Archives Canada de reproduire, publier, archiver, sauvegarder, conserver, transmettre au public par télécommunication ou par l'Internet, prêter, distribuer et vendre des thèses partout dans le monde, à des fins commerciales ou autres, sur support microforme, papier, électronique et/ou autres formats.

L'auteur conserve la propriété du droit d'auteur et des droits moraux qui protège cette thèse. $\mathrm{Ni}$ la thèse ni des extraits substantiels de celle-ci ne doivent être imprimés ou autrement reproduits sans son autorisation.
In compliance with the Canadian

Privacy Act some supporting forms may have been removed from this thesis.

While these forms may be included in the document page count, their removal does not represent any loss of content from the thesis.
Conformément à la loi canadienne sur la protection de la vie privée, quelques formulaires secondaires ont été enlevés de cette thèse.

Bien que ces formulaires aient inclus dans la pagination, il n'y aura aucun contenu manquant.

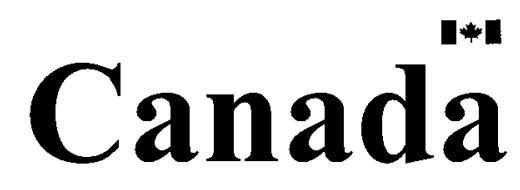


Acknowledgments:

This thesis would not have been possible without the invaluable guidance and insight of Sheryl Boyle, and the generous patience and support of my family. 


\begin{abstract}
This thesis examines the concept of monstrosity for its ability to inform brownfield remediation architecture; the theme of metamorphosis and the idea of the grotesque body are used to develop the design of a phytoremediation strategy and adaptive reuse at the abandoned CN yards in Point Saint-Charles, Montreal.

Conventional brownfield remediation practices replace existing soil or seal contamination with a cap; transformation does not occur. Instead, change happens through replacement or concealment and the site's ability to convey its significance is lost.
\end{abstract}

However, when informed by the concept of metamorphosis, remediation is able to reveal the act of healing, provoking critical reconsideration of the post-industrial urban environment. Emerging phytoremediation methods transform soil in situ, while questioning the boundaries between nature and technology.

Through legible transformation, brownfields are able to demonstrate the ambiguous but pervasive role that technology plays in the post-industrial city; the act of remediation thus extends beyond the specific site of contamination to influence broader discourses concerning the meaning of technology. 
TABLE OF CONTENTS

Acknowledgments

$\begin{array}{ll}\text { Abstract } & \text { iii }\end{array}$

List of Figures $\quad$ v

$\begin{array}{lll}1.0 & \text { Introduction } & 1\end{array}$

2.0 Monstrosity

2.1 Medieval Monsters 5

2.2 Monstrosity and Architecture 9

2.3 Monstrous Corporeality 12

3.0 Mad Scientists and their Monstrous Creations

$\begin{array}{lll}3.1 & \text { Origins } & 15\end{array}$

$\begin{array}{lll}3.2 & \text { Alchemists } & 16\end{array}$

3.3 Monstrosity in Mary Shelley's Frankenstein 21

3.4 Cinematic Representations of Frankenstein 25

4.0 Brownfields and Phytoremediation

4.1 Brownfields 29

4.2 Phytoremediation 31

4.3 Case Study: Duisberg-Nord 35

5.0 The Site and Design

5.1 Point Saint-Charles and the Grand Trunk Railway Shops 40

5.2 The Monstrous Recreational Centre 43

6.0 Conclusion 63

7.0 Bibliography 
Figure 1: $\quad$ Aerial Photograph of Point Saint-Charles

Google Earth. Vers. 4.1 $5^{\text {th }}$ May $2007<$ http://earth.google.com/>

Figure 2: $\quad$ Detail of Site Plan, by Author

Figure 3: $\quad$ Photograph of Existing Facade, by Author

Figure 4: $\quad$ Axonometric Detail, by Author

Figure 5: Section through Trellis, by Author

Figure 6: Photograph of Existing Coal Trough, by Author

Figure 7: Section through Trough, by Author

Figure 8: Elevation of Furnaces, by Author

Figure 9: $\quad$ Vignette, by Author

Figure 10: Untitled, by Author

Figure 11: Site Plan, by Author

Figure 12: Ground Floor Plan, by Author

Figure 13: Second Floor Plan, by Author

Figure 14: Top Level Floor Plan, by Author

Figure 15: Section through Engine Room, by Author

Figure 16: Section through Recreation Centre and Convention Centre by Author

Figure 17: Section through Pool Room, by Author

Figure 18: Elevation of East Façade, by Author

Figure 19: $\quad$ Axonometric Detail, by Author

Figure 20: Vignette, by Author 


\subsection{INTRODUCTION}

The remediation of brownfields offers opportunities for architecture to demonstrate the ambiguous and pervasive role that technology plays in the urban environment. Designs that critically employ recent advances in remediation technology, such as phytoremediation, can heal the scars of industrialization in a manner that is ecologically responsible, financially feasible and, most importantly, conceptually legible to the public. Such designs enable society to witness, understand and participate in the healing of the site; architecture questions the dichotomous opposition between nature and culture, while fostering a public spirit of environmental responsibility. The act of remediation thus extends from the specific site of contamination to influence broader discourses concerning the meaning of technology. This thesis investigates the potential for the architecture of brownfield remediation to further a critical understanding of technology's relationship with the post-industrial city.

The investigation is developed through an exploration of the construct of monstrosity. In examining the medieval epistemology of the monstrous, it is shown that the monsters of the Middle Ages do not, as is often claimed, represent the ignorance and superstitions of pre-modern Europe; rather, they serve as meaningful demonstrations. From their marginal position, they are able to defy rational categorization. The monstrous are not mere visual aberrations; rather, they are contended to serve the crucial function of challenging conventional boundaries, thereby encouraging critical discourse. To relate the concept of monstrosity to the discipline of architecture, and to the field of brownfield remediation specifically, this thesis explores issues of corporeality and 
tectonics in architecture, as discussed in Marco Frascari's Monsters of Architecture: Anthropomorphism in Architectural Theory.

The discourse of monstrosity and corporeality is then traced to menstruation, which throughout much of western history was perceived and portrayed as monstrous. The rich variety of meanings attributed to menstruation is argued to demonstrate the important yet ambivalent position this aspect of human reproduction held in western culture. Menstruation was interpreted as demonstrating the physical and emotional inferiority of women; monstrously, however, it also demonstrated the power women had in the reproductive cycle. Menstruation served as a medieval reminder of the necessity of women to procreation; their absence, in narratives of artificial creations, was thought to result in monstrous offspring.

The monstrosity of these creations is attributed to their synthetic origins. The act of artificially creating life entails the assumption of powers prohibited to humanity; this transgression is demonstrated by the monstrous corporeality of the resulting creations. The narratives of these creatures are argued to function as antirational critiques. More specifically, later incarnations of the narrative such as Mary Shelley's Frankenstein: a Modern Prometheus, act as challenges to an increasing faith in technology and progress, while questioning the boundaries of human corporeality. The monster in Shelley's nineteenth century novel simultaneously represents the dangers of technology unguided by ethics, while confusing conventional delineations between human and inhuman. This representation of monstrosity, and the challenges it poses to classical conceptions of corporeality, are used in this thesis to critically inform the architecture of remediation. 
It is then argued that the presence of contaminated urban land is the legacy of an uncritical faith in linear progress and a pervasive materialist ideology. Existing on the margins of the urban consciousness, brownfields ${ }^{*}$ are contended to act as the postindustrial city's monster, demonstrating the failures of rationalist planning and the consequences of an unsustainable emphasis on economic productivity. Emerging remediation methods, especially phytoremediation ${ }^{\dagger}$, can also be interpreted as monstrous: occupying the frontiers of scientific research, these methods question the delineations between nature and technology. When engaging the public in the process of remediation, these technologies also have the potential to act as demonstrations, imbuing the site and its decontamination with meaning.

The potential of these new technologies is explored through a critical analysis of Latz + Partner's Landschaftpark Duisburg Nord, an adaptive reuse and remediation of a heavy industrial facility in northwestern Germany. Attention is devoted to the project's demonstrative capacities; the act of remediation is clearly legible, at times even participatory. It is contended that this engaging aspect of the project's character enables it to address more than the contamination of its specific site; as a critical demonstration, the Landschaft Park is able to further local pride of place, while contributing to a broader critique of the post-industrial landscape. These claims are supported primarily through analysis of the project's sensitive materiality and reuse of existing structures; by

\footnotetext{
"In this thesis, the term 'brownfield' refers to the sites of real or perceived contamination, which have been left behind in the wake of polluting industries; the term refers to both the buildings of these sites and to the land they occupy.

${ }^{\dagger}$ Phytoremediation is the process through which soil and water-born contaminants can be absorbed or neutralized by vegetation; it is an increasingly viable means to remediate polluted brownfields.
} 
developing themes of transformation through these means, Latz + Partners creates monstrous architecture.

The insights gained from this investigation of monstrosity, architecture and corporeality then inform the design of a community recreational centre in Montreal. Located in Point-St.-Charles, immediately southwest of the city's core, the site of the proposal is currently (un)occupied by defunct rail yards, shops, and other related structures. The site is characteristic of brownfields: over a century of industrial activity has left the property ecologically devastated, while a more recent decline in the area's manufacturing sector has adversely affected the socio-economic health of neighbouring communities. The proposal seeks to treat these ailments through the adaptive reuse of the abandoned facility's engine and boiler room; reanimated as a community recreational centre, the building is simultaneously transformed into a demonstration of the process of remediation. By revealing the process of remediation, the design provokes critical reconsideration of technology's role in the post-industrial city. 


\subsection{MONSTROSITY}

\subsection{Medieval Monstrosity}

Medieval European representations of the monstrous contribute greatly to contemporary conceptions of monstrosity. The monsters of the Middle Ages, however, remain frequently misunderstood. When interpreted literally, these monsters appear as signs of ignorance and fear; pre-modern Europe is seen as having expressed in its monsters an actual worldview, one dominated by superstition and xenophobia. This supposed lack of sophistication contributes to perceptions of the era as an aberration in the development of Western civilization: the 'Dark' Ages between antiquity and the Renaissance. Historians Bettina Bildhauer and Robert Mills remark:

The Middle Ages as a period continually threatens to disrupt modernity from its position on the edges of history: if the Middle Ages is popularly imagined as a time full of monsters, then it can also be said to operate itself as a kind of histiographic monster. ${ }^{1}$

The authors propose that the monstrous character of the Middle Ages is due to both the era's peripheral status in conventional scholarship, and to the challenges the medieval mindset poses to modern rationalism. As a period in Western history, the Middle Ages are a demonstration of the limits of the myth of progress.

Mills and Bildhauer's claim that the Middle Ages act as a monster elucidates one of the fundamental characteristics of monstrosity. Monsters are marginal, and are thus able to resist categorization. Their marginality enables them to act as demonstrations: by confusing boundaries, monsters prompt critical reflection of conventional delineations. Their demonstrative role is evidenced by the etymology of the word 'monster', which traces its origins to the Latin verb montrare, meaning 'to show.' The messages

\footnotetext{
${ }^{1}$ Bettina Bildhauer and Robert Mills. "Introduction: Conceptualizing the Monstrous" The Monstrous Middle Ages. Bettina Bildhauer and Robert Mills, eds. Toronto: University of Toronto Press, 2003) 3.
} 
conveyed by these demonstrations vary; as historian Lisa Verner notes, "The monster always 'shows,' but what it shows, the variation of meaning it is allowed to express symbolically, does change. $" 2$ Over the course of the Middle Ages, monsters gain a variety of meanings, serving as spatial and temporal markers, while confusing conventional dichotomous categories. The boundaries most questioned by medieval monsters are those defining humanity. As Bildhauer and Mills remark, "Collapsing the distinctions that create meaning by combining a thing and its opposite in one body, medieval monsters were frequently imagined as both human and not-human, animal and not-animal."3 By upsetting perceptions of what it means to be human, medieval monsters and their descendants function as a "vehicle for human introspection."4

One variety of monsters that demonstrates this function is the Giant. Medievalist Jeffrey Cohen describes the Giant as an 'intimate stranger':

He cannot be fully banished from, or integrated into, those identity categories that his body constructs. The giant is at once a seemingly monolithic representation of otherness and a figure whose indomitable corporeality suggests the difficulty of being merely human in a world that demands the austere discipline of minute self-regulation. ${ }^{5}$

The Giant's scale separates him from humanity, yet by provoking reconsideration of the corporeal restrictions imposed by civilized society, he is simultaneously similar. His inhuman size enables him to demonstrate the limits placed on an individual's corporeality by the restrictive ideals of physical self-discipline.

Scale serves the giant, as hybridism and metamorphosis serve other varieties of medieval monsters: unlikely conjunctions and transformations are also able to provoke

\footnotetext{
2 Verner 6.

${ }^{3}$ Bildhauer and Mills 14.

${ }^{4}$ Verner 156.

${ }^{5}$ Jeffrey Jerome Cohen. Of Giants: Sex, Monsters and the Middle Ages. (Minneapolis: University of Minnesota Press, 1999) xiv
} 
critical reflection. Hybridism is exhibited by such monsters as the cynocephali, creatures whose canine heads and human bodies represent a combination "of the familiar and the strange." In the most detailed account of the cynocephali, from the Travels of John Mandeville, their social behaviour is also portrayed as hybrid; their society is highly regimented and devout, yet as medievalist Sarah Salih notes, "They have some alarming habits which might cast doubt on their full humanity: they wear only loincloths and they eat their prisoners." The unlikely combination of human and animal corporeality is echoed in the creatures' behaviour, which is at once both civil and barbaric. Similar to the unexpected scale of the giant, the surprising conjunctions inherent in the cynocephali provoke critical reflection of what it means to be human, both corporeally and socially. They demonstrate the indeterminacy of humanity.

The theme of metamorphosis is also used in medieval representations of the monstrous to demonstrate this indeterminacy; transformations of the human body implicitly challenge conventions regarding human identity. These changes, like the unexpected scale of the giant or the hybridism of the cynocephali, elicit reconsideration of what constitutes humanity. Although in some ways related to the concept of hybridism, metamorphosis is distinct; as medievalist Caroline Walker Bynum states, The hybrid expresses a world of natures, essences, or substances (often diverse or contradictory to each other), encountered through paradox; it resists change. Metamorphosis expresses a labile world of flux and transformation, encountered through story. ${ }^{8}$

\footnotetext{
${ }^{6}$ Sarah Salih. "Idols and Simulacra" The Monstrous Middle Ages. Bettina Bildhauer and Robert Mills, eds. (Toronto: University of Toronto Press, 2003) 126.

${ }^{7}$ Sarah Salih 126.

${ }^{8}$ Caroline Walker Bynum. Metamorphosis and Identity. (Cambridge, MA: MIT Press) 30.
} 
While both concepts "reveal and violate categories," they do so in different ways: "Metamorphosis breaks down categories by breaching them, hybrid forces the contradictory or incompatible to coexist and serve as commentary each on the other." ${ }^{\prime 9}$ The concept of metamorphosis entails a temporal dimension that is unnecessary to hybrids; what makes a hybrid monstrous can be static, while metamorphic monsters, such as werewolves, depend on narrative to convey their monstrosity. In medieval representations of this type of monster, the werewolf is portrayed as a person whose body has been transformed into that of a wolf, yet retains his human memories and intelligence. Despite the retention of these human characteristics, "the ferocity of the wolf shape contaminates the man within and leads him, for all his 'intelligence and memory,' to kill human beings." ${ }^{.10}$ The corporeal transformation entails behavioural metamorphoses as well. Medieval narratives of metamorphosis question the relationship between experience, corporeality and identity. In doing so, they question the ambiguous origins of the human identity.

While the medieval representations of the monstrous have often been regarded as the manifestations of an ignorant and fearful society, their value is increasingly recognised in post-modern scholarship. When understood as challenges to conventional delineations, they are revealed as powerful demonstrations. Monsters employ such means as unexpected scale, hybridism and metamorphosis to provoke critical reflection; as Graham states,

Monsters serve both to mark the fault-lines but also, subversively, to signal the fragility of such boundaries. They are truly 'monstrous' - as in things shown and displayed - in their simultaneous demonstration and destabilization of the demarcations by which

\footnotetext{
${ }^{9}$ Bynum 31.

${ }^{10}$ Bynum 97.
} 
cultures have separated nature from artifice, human from non-human, normal from pathological. $^{11}$

Medieval conceptions of monstrosity cannot be dismissed as frivolous and antiquated; in postmodern society, they find renewed relevance. Pertinent to the discourse of alterity, monstrosity demonstrates the indeterminacy of the human identity. The monstrous can thus be employed in the search for architectural strategies that elicit critical reflection of humanity.

\subsection{Monstrosity and Architecture}

Architectural designs involving brownfield remediation benefit from an engagement with the discourse of monstrosity, especially when the project includes adaptive reuse. When informed by this concept, the act of remediation becomes legible, imbuing the project with a demonstrative capacity that enables it to challenge preconceptions and provoke criticism. By engaging the public in this manner, the architecture of remediation is able to extend the act of healing from specific contaminated sites, to address broader issues facing the post-industrial urban environment.

In Monsters of Architecture: Anthropomorphism and Architectural Theory, Marco Frascari contends that architectural details "are the semiotic tools for the critical reading of architectural narrations;",12 it is here that architecture is able to demonstrate. The joints of construction, he explains, are "architectural monsters that make people think about

\footnotetext{
${ }^{11}$ Garham, 11

${ }^{12}$ Marco Frascari, Monsters of Architecture: Anthropomorphism and Architectural Theory (Lanham, MD: Rowan and Littlefield, 1991) 11.
} 
their environment." ${ }^{, 13}$ When the architecture of remediation is conceived in this way, the intersection between recent interventions and existing structures is especially demonstrative, encouraging critical reconsideration of new and old alike. By manipulating the tension between the two, it is possible to reveal aspects concerning both. These joints emphasize physical differences between two periods of construction; in doing so, they also make legible two interconnected architectural narratives. The narratives told by these joints demonstrate the concepts of the cultures of which they were a part, and how these concepts have transformed over time. As "compelling demonstrations of how we inhabit the world, ${ }^{, 14}$ architectural details elicit critical reconsideration of society's relationship with its environment.

With the re-inhabitation of brownfields, the tension between the new intervention and the existing structure is itself demonstrated, confusing linear chronologies. Previous polluting operations inform the act of remediation, which in turn influence perceptions of the industrial past. In this sense, the new intervention acts as a subjective medium for remembering the site's heritage, while it is itself shaped by prior activities. At the margins between new and old, architecture is able to demonstrate the bonds between the two, thereby challenging the authority of temporal delineations.

In addition to being a potentially monstrous hybrid of old and new construction, remediation architecture can also demonstrate metamorphosis. While conventional methods of site rehabilitation, such as hauling and capping, produce change through replacement and concealment, the use of emerging phytoremediation techniques enables

\footnotetext{
${ }^{13}$ Frascari 16.

${ }^{14}$ Frascari 22
} 
transformation. The phytoremediation of contaminated soil in situ, as well as the reuse of existing structures, demonstrates change through metamorphosis. The physical components of a site need not be removed, nor masked. Instead, they can be retained but transformed. This metamorphosis can be demonstrated architecturally; the remediation process can be designed to show itself in an engaging manner, one that would provoke critical reconsideration of society's inhabitation of its environment. This monstrous intent is manifested as the exposed systems of the intervention. Revealing its inner workings, the intervention acts like the grotesque body described by Marco Frascari:

The grotesque body is a body in the act of becoming. It is never finished, never completed; it is continually built, continually created; and it is the principle of others' bodies. The logic of a grotesque image ignores the smooth and impenetrable surface of the neoclassical bodies, and magnifies only excrescences and orifices, which lead into the bodies' depths. The outward and inward details are merged. Moreover, the grotesque body swallows and is swallowed by the world. This takes place in the openings and the boundaries, and the beginning and end are closely linked and interwoven. ${ }^{15}$

Such a vision of monstrous corporeality offers a fruitful source of inspiration for the design of remediation strategies; when engaged in a metonymic relationship with human corporeality, remediation architecture is better able to demonstrate its intentions. In this context, the relationship between architecture and human corporeality extends beyond mere formal metaphors; architecture is construed to act as a body: it becomes a clearly legible system of organs. Consuming, digesting and excreting, remediation architecture becomes monstrous; demonstrating the process of healing, while revealing the maleability of the physical environment.

\footnotetext{
${ }^{15}$ Frascari 32.
} 


\subsection{Monstrous Menstruation}

An aspect of human corporeality that bears particular relevance to the discourse of monstrosity is menstruation. As Elaine Graham notes, female corporeality defies the categories constructed by the predominantly male establishment: "The permeability of the limits of the female body - giving off regular menstrual discharge, capable of bearing another life within its own body, changing shape during pregnancy - all contribute to the anxiety of the patriarchal mindset." ${ }^{\text {16 }}$ Monstrously, menstruation was seen as evidence of the inferiority of women, while simultaneously demonstrating their power in the reproductive cycle.

Before the medical discoveries of the modern era, menstruation was one of the most mysterious aspects of female physiology. By the time its purpose was scientifically understood, western civilization had already developed a remarkably varied, oftencontradictory tradition of speculation concerning the topic. While much of this montrous discourse surrounding menstruation portrayed it as a danger, the threat it posed was rarely thought to be directed toward the one who was actually menstruating. Rather, this part of the female reproductive cycle was considered to be more of a menace to others. In her study of attitudes towards menstruation in pre-modern Europe, historian Patricia Crawford observes that many parties had cause to fear menstruating women, including virgins, expectant mothers, infants, bees, and vegetation. ${ }^{17}$ Those with the most to fear from menstruation, however, were men. As Crawford notes, "menstruation posed particular dangers to a woman's sexual partner. One extreme work of 1506 claimed that

\footnotetext{
${ }^{16}$ Graham 54

${ }^{17}$ Crawford, Patricia Attitudes to Menstruation in Seventeenth century England 59
} 
intercourse during menstruation would be fatal to the husband, so poisonous was the monthly flow." Another disincentive was the belief that children conceived through such inappropriate means "would be either deformed or a monster." 18 To conceive a child during this time violated the laws of nature, a sin that is demonstrated by the monstrous newborn, who was, as Graham states: "the tangible, corporeal manifestation of sinful and disobedient acts." ${ }^{.19}$

While menstruating women were a cause for concern, public opinion was generally more ambivalent regarding the powers of menstrual blood. Many were convinced of its potential magical applications; Crawford describes some of its possible uses:

It had a role in love magic: harlots could bewitch their lovers with it, and ingredients for love potions were to contain those parts in which venereal appetite was vigorous, which included the menstrues. It might help or hinder contraception. The menstrual clothes, washed in new milk and hung on a hedge for some time, might make a woman fruitful. Menstrual blood, applied to the 'naturall place', would hinder contraception. It might be used to cure the bights of mad dogs and the falling sickness and might drive away agues. It might remove birthmarks or red spots. Its power might protect the threads of a garment from buring, and avert natural disasters such as tempests, hail and lightning. ${ }^{20}$

Despite menstrual blood's surprising versatility, it also possessed negative connotations. Menstruation was thought to serve as a means of purification: women, being inherently inefficient, were incapable of consuming all the blood their bodies produced and the excess had to be shed. Menstrual fluid was thus likened to other excreta: as poisonous waste, it released "unclean and venomous fumes." ${ }^{21}$ This theory regarding the meaning of menstrual fluid not only provided a (somewhat) medical

\footnotetext{
${ }^{18}$ Crawford, Patricia Attitudes to Menstruation in Seventeenth century England 62

${ }^{19}$ Graham, 48

${ }^{20}$ Crawford, Patricia Attitudes to Menstruation in Seventeenth century England 60

${ }^{21}$ Crawford, Patricia Attitudes to Menstruation in Seventeenth century England 59
} 
explanation, it could also be used to support the subordination of women. As Crawford argues, "menstruation was seen as a planned consequence of women's predetermined sedentary domestic lives." ${ }^{22}$ While robust men could sweat out their impurities, delicate women had to rely on other less decent means, which were also perceived to have the unfortunate side effect of clouding their minds. Monstrously, menstruation was seen as a threat, while it simultaneously demonstrated the inferiority of women. Perhaps most monstrously, menstruation also served to demonstrate the power women had in the reproductive cycle. Menstruation demonstrated the ability to bear children, an act of which a man alone was incapable.

\footnotetext{
${ }^{22}$ Crawford, Patricia Attitudes to Menstruation in Seventeenth century England 72
} 


\section{MAD SCIENTISTS AND THEIR MONSTROUS CREATIONS}

\subsection{The Origins of Mad Scientists}

Human reproduction without women is the subject of numerous narratives in western culture. Myths of male-only procreation generally present the act as immoral; the sin is demonstrated by the monstrous corporeality of the offspring. These monstrous creations confuse conceptions of humanity by violating various boundaries, such as those between nature and artifice, man and beast, and life and death. Their legacy is ancient, and can be traced from antiquity to the present: a current incarnation is the unfortunate and often dangerous creation of the mad scientist.

The archetype of the mad scientist became popular in nineteenth century literature, as a critique of society's increasing dependence on technology. Mary Shelley's Frankenstein: a Modern Prometheus, is often acknowledged to be the most influential incarnation of the archetype; the archetype's origins, however, can be traced to much earlier figures in western culture. One of the earliest influences is alluded to in the title of Shelley's novel: the ancient Greek myth of Prometheus. While many Greek myths contain examples of hubris being met with retribution, the story of Prometheus is of particular relevance to the development of the mad scientist narrative. This is due to its emphasis on the dangers of forbidden knowledge: the ability to create fire. In the myth, Prometheus steals this secret knowledge and gives it to humanity. Social and Pastoral Theologist Elaine Graham compares the mythological figure to Shelley's character, Victor Frankenstein: 'Like his ancient predecessor, the 'thief of fire', Victor steps over the boundary between taxonomy and manipulation by summoning up the 'spark of 
being', and unleashes the dangerous energy by which life itself is generated."23 The ability to manipulate the boundaries between life and death is portrayed as a power forbidden to humanity; the modern mad scientist is presented as being most dangerous when violating this threshold.

The threat this violation poses to humanity is considered most perilous when it involves the creation of new beings. These monsters, neither human nor inhuman, violate the boundaries defining the species, thereby questioning its identity. Many precedents of the mad scientist also created monsters; earlier examples include Hebraic golems, clay humanoids animated by precocious rabbis, and the homunculi of medieval alchemists.

\subsection{Alchemists}

Just as many of the disciplines of modern science have their origins in alchemy, so too can numerous aspects of the mad scientist be traced to the figure of the alchemist. Classical and Biblical narratives also concern themselves with the dangers of hubris, forbidden knowledge, and challenges to the divine monopoly on creation. It is in the Medieval European discourse surrounding alchemy, however, that a dichotomy between faith and rational inquiry, rather than simply human ambition, begins to dominate. While alchemists were occasionally celebrated for their achievements, they were more often interpreted and portrayed as a threat to the clergy's authority. Foreshadowing the dubious reputation of their descendant the mad scientist, alchemists were represented as sinister characters, "most likely in league with the devil."24 Monstrously, they were both

\footnotetext{
${ }^{23}$ Elaine L. Graham, Representations of the post/human: Monsters, aliens and others in popular culture (New Brunswick, NJ: Rutgers University Press, 2002) 77.

24 Rosalynn D. Haynes. From Faust to Strangelove: Representations of the Scientist in Western Literature. (Baltimore: Johns Hopkins University Press, 1994) 10.
} 
feared and respected; English literature professor Barbara Benedict notes, "The mad scientist inherits this ambiguous social status of illegitimate but compelling authority."25

Alchemy is popularly conceived as a field preoccupied with the transmutation of base metals into gold; during the late Middle Ages, however, other powers of metamorphosis were also associated with the field. Regarding the lineage of mad scientists and their monstrous creations, the most significant of these is that of controlling the boundary between life and death. It is also the aspect of the field most in opposition to the tenets of religious authority: “The alchemist's search for the philosopher's stone conferring immortality," remarks Benedict, "ostentatiously ignores the Christian doctrine of resurrection through Christ." 26 Control over the forces of life included more than preservation from death; some alchemists, such as Paracelsus, claimed to possess the power to create life in the form of a homunculus. ${ }^{27}$ His monstrous creation was supposedly made "from sperm incubated for forty weeks in horse manure."28 As noted by scholar Rosalynn D. Haynes, this, like the promise of earthly immortality, was also "perceived as a threat to the divine basis of life expounded by the church and," she continues, "much the same furor attended the attempts to produce a homunculus as obtains today over in vitro fertilization or genetic engineering." ${ }^{29}$ Similar to modern narratives regarding synthetic life, popular accounts of alchemical creations generally emphasize the "sense of guilt associated with these attempts to emulate the divine

\footnotetext{
${ }^{25}$ Robert C. Leitz, and Kevin L. Cope. Imagining the Sciences: Expressions of New Knowledge in the "Long" Eighteenth Century. (New York: AMS Press, 2004) 62.

${ }^{26}$ Leitz and Cope 62.

${ }^{27}$ Leitz and Cope 63.

${ }^{28}$ Cecil Helman. "Dr. Frankenstein and the Industrial Body: Reflections on 'Spare Part' Surgery" Anthropology Today, Vol. 4, No. 3. (Jun., 1988) 14.

${ }^{29}$ Haynes 13 .
} 
prerogative:" alchemists inevitably found retribution for their reckless ambition. ${ }^{30}$ As Benedict states, alchemists "fostered a popular tradition that dubbed the manipulation of nature immoral;";1 a theme that recurs in such later literary works as Frankenstein, as well as in numerous films of the twentieth century. In these narratives, the immorality of violating the boundaries between nature and artifice is demonstrated by the monstrous corporeality of the unfortunate creation.

The dichotomous relationship constructed in these works typically associates nature with primordial purity and the divine, while technology is linked to cold rational inquiry and reckless human ambition. The "medieval suspicion of knowledge"32 that casts alchemists in a sinister light recurs regarding subsequent incarnations of the mad scientist archetype. Alchemists, for their part, challenged not only the evil connotations attributed to their field, they also debated the "universal proposition that art is inferior to nature. ${ }^{33}$ Science historian William Newman notes that, in response to the criticism they faced, alchemists "developed counter arguments adopting a radical view of technology in which man assumed extraordinary power over nature.” Protagonists of alchemy asserted that "Man's ability to transform the natural world is virtually unbounded." ${ }^{34}$ This confidence foreshadows both the optimism of the science fiction genre, as well as the fears of post-modern environmentalism. The grand promises made by alchemists did little to assuage the insecurities of the clergy and public; their hyperbolic claims were seen as further evidence of the corrupting influence of the dark arts they studied. By

\footnotetext{
${ }^{30}$ Haynes 13.

${ }^{31}$ Leitz and Cope 62.

${ }^{32}$ Haynes 10 .

33 William Newman. "Technology and Alchemical Debate in the Late Middle Ages" Isis Vol. 80, No.3. (Sep., 1989) 429.

${ }^{34}$ Newman 429.
} 
promising what most would consider miracles, alchemists were perceived as challenging the authority of the church and prevailing religious beliefs.

An aspect of alchemical thought that was particularly offensive to medieval sensibilities was its ambition to create life; the alchemists who dared to attempt such a monstrous act assumed powers reserved for the divine. The artificial creation of life is a recurring theme in many of the narratives involving the archetype of the mad scientist; its persistence is due to more than the violation of religious taboos that it presents. As cultural historian Christopher Frayling notes, "Biology has tended to arouse the most passions, since it is about the basis of human life itself."35 By attempting to create life, alchemists and their successors confused the boundary between artifice and nature at a corporeal level; their monsters challenged conceptions of who was, and what was not, human. Even more offensive to popular sensibilities is their belief that their creations could equal, or even be superior to, their natural counterparts. Alchemists, with their confidence in the potential of technology, were unique among medieval scholars; as Newman observes:

Alchemical writers, unlike those in the mainstream of the Scholastic tradition, were willing to argue that human art, even if it learned by imitating natural processes, could successfully reproduce natural products or even surpass them. In so doing, the alchemists of the Middle Ages developed a clearly articulated philosophy of technology, in which human art is raised to a level of appreciation difficult to find in other writings until the Renaissance. $^{36}$

While many of their medieval contemporaries viewed technology as inferior to nature and potentially detrimental to society, alchemists held it in higher esteem. They accordingly believed it was possible for them to create a superior being; the alchemists'

\footnotetext{
${ }^{35}$ Christopher Frayling. Mad, Bad and Dangerous? The Scientist and the Cinema. (London: Reaktion Books, 2005) 38.

${ }^{36}$ Newman 424.
} 
successors, the mad scientists, shared similar ambitions. Narratives of either archetype engaged in such attempts, however, rarely portray success. Their creations are generally flawed; their inferiority is a demonstration of their questionable origins. While some artificial life is represented as being more powerful or cunning than its natural counterparts, it is also shown to be somehow handicapped, deformed, miserable, or even dangerous. As unfamiliar 'others' existing between the boundaries of life and death, between natural and artifice, these creations are monstrous.

Alchemy's confidence in the potential of human achievement challenged prevailing medieval views concerning what "was considered proper for man to know." 37 Their fondness for science, though perhaps at times overly optimistic, can still serve as inspiration for architects. Engaged in the sensitive acts of transforming the environment and manipulating materials, architects require confidence that their interventions do not necessarily constitute a corruption of supposedly 'perfect' existing conditions. They must also avoid, however, the arrogance popularly attributed to alchemists and mad scientists; narratives portraying the dangers of technology cannot be rejected as simply the manifestations of an anxious and sceptical society. Instead, they demonstrate the presence of the dichotomy that has been constructed opposing nature and faith, with rational inquiry and technology.

Another boundary that both architecture and alchemy blur is that between theory and practice. The two disciplines concern themselves with making visible the invisible; architects, like alchemists, demonstrate in their physical work intangible concepts and intentions. Just as medieval alchemists had a "familiarity with the elements and a

\footnotetext{
${ }^{37}$ Haynes 14.
} 
philosophy of how they should be joined, ${ }^{, 38}$ so too do architects possess an understanding of construction materials, as well as convictions concerning their assembly. Architectural details demonstrate the intentions of the architect; as Marco Frascari notes, "These artefacts are produced by the converging of functions in a representation where reason and construction are unified by a conception." ${ }^{39}$ Similar to architectural designs, the creations of alchemists, as well as those of their succesors, demonstrate a perspective of the world in which the boundaries between nature and artifice are malleable and often indistinct.

\subsection{Monstrosity in Mary Shelley's Frankenstein: a Modern Prometheus}

Possibly the best known narrative to question the boundaries between nature and artifice is Mary Shelley's 1816 novel Frankenstein: a Modern Prometheus; as Rosalynn Haynes notes, Victor Frankenstein "has become an archetype in his own right, universally referred to and providing the dominant image of the scientist in twentieth century fiction and film.. ${ }^{40}$ The same is true of Frankenstein's creation, the Monster. The persistence of the two figures in popular culture can be attributed to their ambiguity, which results from the tensions inherent in both. As conflicted characters, they resist categorization, and thus serve as demonstrations of the limits inherent in established definitions of humantiy. In this sense, they are monstrous. Shelley's account of artificial creation is distinguished from its predecessors -and many of its successors- by this pervasive ambivalence: unlike other narratives dealing with similar themes, Frankenstein refuses to deliver conclusive answers to the questions it raises. The ability of

\footnotetext{
${ }^{38}$ Johnston 11.

${ }^{39}$ Frascari 12

${ }^{40}$ Haynes 92.
} 
Frankenstein to question the role of technology, while challenging constructed dichotomies, grants the narrative particular relevance to the discourse of brownfield remediation.

Shelley's novel continues the tradition of portraying the dangers of human technology, especially those associated with the creation of monstrously artificial life. Her representation of the scientist, however, is more nuanced than most of its predecessors: Victor Frankenstein is conflicted, and questions the ethical implications of his actions. Unlike previous depictions of the mad scientist and his unfortunate creation, Shelley creates an "entirely secular and unredeemed situation," ${ }^{, 41}$ in which both the monster and his creator are morally ambiguous, and religious considerations are all but absent.

This ambiguity is present within Frankenstein himself, whose character exhibits a complexity that is unprecedented in the tradition of the mad scientist archetype. Unlike previous incarnations of the archetype, Mary Shelley's protagonist exhibits characteristics associated with both heroes and villains. Victor Frankenstein's conflicted relationship with the monster is revealing of the moral ambiguity of his character: he both pities and abhors his creation. When asked by the monster to create a mate, Frankenstein is initially compassionate:

His words had a strange effect on me. I compassionated with him, and sometimes felt a wish to console him; but when I looked upon him, when I saw the filthy mass that moved and talked, my heart sickened, and my feelings were altered to those of horror and hatred. I tried to stifle these sensations; I thought that, as I could not sympathise with him, I had no right to withhold from him the small portion of happiness which was yet in my power to bestow. ${ }^{42}$

\footnotetext{
${ }^{41}$ Haynes 102.

42 Shelley 149 ,
} 
Towards the end of the narrative, however, Frankenstein is consumed by revenge, and betrays his promise to his creation, despite his knowledge of the wrath such an act would likely incur on his loved ones.

In addition to Victor Frankenstein's conflicted conscience, Shelley has granted him the seemingly competing qualities of a rational scientist and a Romantic. He demonstrates calculating rationalism, yet is frequently overcome by his emotions. Frankenstein shows the extent of his detachedness when describing his methods of research:

Darkness had no effect upon my fancy; and a churchyard was to me merely the receptacle of bodies deprived of life, which, from being the seat of beauty and strength, had become food for the worm. Now I was led to examine the cause and progress of this decay, and forced to spend days and nights in vaults and charnel houses. My attention was fixed upon every object the most insupportable to the delicacy of human feelings. ${ }^{43}$

Unlike most, Frankenstein is unperturbed by the decay of the human body, and, in order to advance his research, is willing to violate the sanctity of the dead by their disinterment. In other instances, however, Frankenstein reveals himself as highly irrational. He pursues his research with such passion that his health suffers, and upon successfully animating his creation, he panics and flees. These contradictory facets of Frankenstein's personality have enabled his character to have a profound influence on the development of the mad scientist archetype. As Haynes notes, "By bringing together the apparently opposite qualities of the scientist and the Romantic visionary, Mary Shelley not only enriched immeasurably her depiction of the scientist but extended the basic Romantic protest against materialism and rationalism. ${ }^{, 44}$ By relentlessly pursuing his ambitions without first pausing to consider the ethical implications of his actions, Victor

\footnotetext{
${ }^{43}$ Shelley 55.

${ }^{44}$ Haynes 100.
} 
Frankenstein demonstrates an uncritical faith in the power of science, as well as an arrogance regarding his ability to control the outcomes of his experiments. Mary Shelley's protagonist thus functions as a critique of society's increasing secularization and industrialization.

The other leading figure in Frankenstein, the monster, also merits attention. Similar to Victor Frankenstein, the monster's character is more developed than in prior works dealing with the theme of artificial life. Most significant, is the monster's ability to speak. Previous human-made creatures such as the golem or the homunculi were often represented as lacking the power of speech; this was part of what distinguished them from their human creators. The monster in Shelley's Frankenstein, however, cannot only speak -he can express his views articulately as well. Shelley contrasts his eloquent command of language with his "unearthly ugliness." 45 The monster himself is well aware of this aspect of his condition; when he initially seeks the companionship of the family he had been observing, he waits to enter their home until the blind father is alone. In describing to the father how others have treated him thus far, he remarks, "A fatal prejudice clouds their eyes, and where they ought to see a feeling and kind friend, they behold only a detestable monster." ${ }^{46}$ This discrepancy between the monster's external physical appearance, and the inner self he is able to communicate through language, is intended to further his monstrosity. By portraying Frankenstein's monster as intelligent and articulate, yet gigantic and grotesque, Mary Shelley attempts to blur the boundaries of who is, and who is not, considered human.

\footnotetext{
${ }^{45}$ Shelley 101.

${ }^{46}$ Shelley 136.
} 
This aspect of the monster's condition is conflicted; Graham claims it articulates "the deep ambivalence of a creature torn between the liberating world of language and reason and the deterministic realm of embodiment and physicality." ${ }^{, 47}$ The dichotomy between culture, as represented by 'language and reason,' and nature, described as 'embodiment and physicality,' is forced together in Frankenstein's creation. The tension between these two constituent parts is what makes his creation monstrous; this tension enables the monster to function as an unsettling critique of humanity.

\subsection{Cinematic Representations of Frankenstein}

The influence of the novel on perceptions of technology is, like its two main characters, ambiguous. "As a piece of popular culture," states social and pastoral Theologist Elaine Graham, "Frankenstein itself inhabits Western cultural imagination as a hybrid and composite monstrosity of disparate and sometimes contradictory fragments and reinterpretations. ${ }^{\prime 48}$ Numerous film adaptations have been made of Mary Shelley's novel, most of which have altered its details in order to better reflect technological advances, as well as the changing tastes of new audiences. Cinematic representations of the Frankenstein are also shaped by the limits and opportunities that distinguish film from literature; in the translation from one medium to another, the meaning demonstrated by the narrative is inevitably altered, and parts of it may even be lost. Film adaptations of Shelley's Frankenstein are generally simplified. Compared to the novel, they devote considerably less effort to developing the characters of either Frankenstein or his

\footnotetext{
${ }^{47}$ Elaine L. Graham. Representations of the post/human: Monsters, aliens and others in popular culture. (New Brunswick, NJ: Rutgers University Press, 2002) 65.

${ }^{48}$ Graham 62.
} 
creation. As a result of this and other differences, film adaptations of Frankenstein are less critical; the movies tend towards sensationalism.

The most famous of these adaptations is Universal Studio's 1931 version, directed by James Whale. As Toumey notes, the narrative was "radically changed" via "many intermediate concepts. ${ }^{\prime 49}$ Successively transformed by the disparate intentions of various authors, the film's narrative and lead characters bear little resemblance to those created by Shelley. While she portrayed Frankenstein as a naïve student, Whale shows him as the conceited Dr. Frankenstein. In describing reactions to the film's portrayal of the mad scientist, Toumey states "Dr. Frankenstein was arrogant, reckless and hysterical, preventing any bond of empathy between the audience and himself."50 The cinematic Dr. Frankenstein lacks the depth of the original; while Shelley's character was able to demonstrate internal conflict and transformation, Whale's portrayal was not.

Some of the most significant discrepancies between the film and novel concern the representation of the monster. In the film, Dr. Frankenstein unknowingly places a criminal's brain into his creation, a mistake that can largely account for the monster's violent behaviour. As Haynes remarks,

The evil character of the Monster is therefore an experimental error rather than the result of Frankenstein's hubris. The implication is that the creation of the Monster per se posed no real or abiding problem, and that with due precautions, a better result could be obtained next time. ${ }^{51}$

In Whale's film, the demonstrative capacity of the monster is thus substantially reduced. Shelley's portrayal provoked speculation regarding the origins of the monster's brutality: in the novel, it is unclear if the monster is corrupted by the cruel treatment he

\footnotetext{
${ }^{49}$ Frayling 426.

${ }^{50}$ Christopher P. Toumey. "The Moral Character of Mad Scientists: A Cultural Critique of Science" Science, Technology, \& Human Values, Vol. 17, No. 4 (Autumn, 1992) 426.

${ }^{51}$ Haynes 102.
} 
endures, or if his violent behaviour is the inevitable outcome of his artificial origins. This uncertainty is lost in the translation to film.

The monster's capacity to demonstrate is further reduced by his inability to speak. While Shelley's monster could articulate his misery, the creation played by Boris Karloff lacks this ability. Graham observes that in imbuing her representation of Frankenstein's creation with the power of speech, Shelley "implicitly challenges his non-human status." ${ }^{, 2}$ As a speaker the monster is on an equal footing with his creator, thereby confusing conventional delineations between human and non-human. This aspect of the creation's monstrosity is absent in Whale's film adaptation; the unsettling juxtaposition between the monster's eloquence and corporeality is replaced by a less provocative accord.

Another aspect of the novel that is lost in the translation to film is that of "multiple and competing authors." 53 In Frankenstein: a Modern Prometheus, Mary Shelley employs an unusually complex narrative structure, one that, as Christopher Frayling notes, "was, and remains, notoriously difficult to adapt to any other medium than the printed page." ${ }^{, 54}$ The monster gives an account of his education and rejection to Frankenstein, who then relays this and other aspects of the story to the sea Captain Walton, who subsequently transcribes that narrative and his own into the letters that form the novel. The novel is constructed as a series of overlapping flashbacks. Anthropologist Christopher P. Toumey believes "a Frankenstein film that faithfully depicted this

\footnotetext{
${ }^{52}$ Graham 65.

${ }^{53}$ Graham 82.

${ }^{54}$ Christopher Frayling. Mad, Bad and Dangerous? The Scientist and the Cinema. London: Reaktion Books, 2005) 109.
} 
narrative structure would soon have quite a bewildered audience." 55 While the simpler narrative structure common to film adaptations may facilitate delivery of the general narrative, its ability to encourage critical contemplation is diminished. The moral ambiguity inherent in Shelley's original narrative structure furthers the novel's critical capacity; the variety of perspectives presented inhibits certainty while eliciting critical speculation. As Graham observes:

This makes it all the more difficult to know definitely who and what is authoritative and normative, and who is intended to excite readers' fear, support, approval and compassion. The reader leaves the arctic wastes, the site of Frankenstein's final confrontation with his creation, undecided as to many endings and resolutions. ${ }^{56}$

The narrative structure of Mary Shelley's Frankenstein is itself monstrous: assembled from the memories of multiple characters, it reinforces the novel's demonstration of the limits of objectivity. Most adaptations of the novel, including Whale's, replace Shelley's complex narrative structure with a simpler one. Cinematic representations of the narrative are portrayed as apparently objective accounts of a linear sequence of events; they are thus unable to demonstrate the pervasive subjectivity inherent in the original.

The monstrous in Mary Shelley's Frankenstein is derived not from any particular aspect of the characters or the plot; rather, monstrosity is expressed through the interrelationships between the constituent parts. Cinematic representations of the narrative tend to miss these opportunities for demonstration; their capacity to elicit critical reflection is subsequently diminished. As with architecture, meaning in Frankenstein is demonstrated by the tension between elements; the assembly communicates more than the sum of its parts.

\footnotetext{
${ }^{55}$ Toumey 421.

${ }^{56}$ Graham 82.
} 


\section{BROWNFIELDS AND PHYTOREMEDIATION}

\subsection{Brownfields}

Modern attitudes toward urban planning favoured the interventions of trained professionals over traditional, more organic patterns of growth. Existing urban fabrics were seen as congested and inefficient; experts, armed with scientific knowledge, were required to improve the situation. Their solutions, however, relied on limited interpretations of the city. Modern planning typically reduced the urban environment to a series of distinct functional components; ideal arrangements were those that promoted efficiency and economic progress. Contemporary critic Peter Weibel examines this bias in his contribution to City Fights: Debates on Urban Sustainability. In his analysis of Tony Ganier's 1907 Une Cité Industrielle, Weibel argues that the urbanist's treatise exemplifies restricted modern conceptions of the city:

Another title for the project was in fact 'City of Labour,' so it is very clear that modern city planning had as a source the idea of labour and production, stemming from the industrial revolution. Three main functions were conceived by Garnier: production, housing and health facilities. The dictatorship of production turned housing and health toward production. Workers had to be healthy and housed to be reliable in the production process. Therefore, production is central to the conception of the city. ${ }^{57}$

This emphasis on quantifiable production denies less tangible aspects of urban life. Modern planning practices assume an absolute knowledge over the workings of the city; the rapid interventions of experts are given license to correct the product of generations of organic development. The resulting creations, like those of literary archetypes who attempt to construct life, can be construed as monstrous. By demonstrating the limits of modern materialism, both function as anti-rational critiques.

\footnotetext{
${ }^{57}$ Mark Hewitt and Susanna Haga. City Fights: debates on urban sustainability. (London: James \& James, 2001) 3 .
} 
The modernist primacy given to objectivity is central to many post-modern critiques; priority is argued to be naively given to the quantifiable, at the expense of the unquantifiable. An emphasis on efficient production thus displaces more subjective concerns such as culture, community and a sense of place. As the results of these priorities, many modern urban environments are perceived as dull and monotonous, if not intimidating and alienating. Where planners had envisioned orderly, hygienic and above all productive landscapes, one is more likely to find decay and ruin. Post-modern planners, having learned from critically examining the works of their predecessors, increasingly favour design strategies that allow for ambiguity and the unexpected, and place greater importance on the intangible aspects of urban life. To realise these ambitions, planners are moving away from prescriptive, function-oriented designs; the limits of professional expertise are increasingly recognised.

Brownfields reside in the margins of the urban consciousness; from their peripheral position, they act as a menacing 'other.' As geographer Christopher De Sousa notes, "From a social perspective, brownfield sites, especially those clustered in industrial districts, are often perceived as areas of high crime, poverty, and places where blight and disrepair have overtaken the community;",58 brownfields are seen as a threat to the integrity of the more decent parts of the city. The social degradation associated with brownfields is often seen as being beyond hope of repair: the remnants of existing communities are sometimes considered to be as much of a liability as the toxins in the soil.

\footnotetext{
${ }^{58}$ Christopher De Sousa, 2
} 


\subsection{Phytoremediation}

Healing the scars left by industrial activity invites experimentation and the use of unconventional methods; the most advantageous techniques are sometimes the most unorthodox. Conventionally, contaminated soil is removed from a site prior to development, or it is left in place and capped by a layer of asphalt or concrete. In either case, the contaminants remain toxic; the threats they pose are only relocated or sealed. Both of these methods, though sometimes the only option, are used far more frequently than necessary, and generally represent wasted opportunities. Emerging decontamination technologies, such as phytoremediation, offer designers the opportunity to treat soil contamination on-site. As Lucinda Jackson describes, these processes "go beyond traditional methods of site clean-up by introducing plants to remediate contamination in place and simultaneously restore and renew habitat." 59 While this can be done before the construction of new projects, the remediation process is best incorporated into the use of the design. Such an integrated approach is beneficial because it accelerates the return of the landscape to public use, while reducing or eliminating the costs associated with soil removal, and enabling a more thorough decontamination than possible through capping. ${ }^{60}$ Furthermore, it offers designers a medium for revealing the history of a site: the specific combination of contamination present in the soil determines the species of plants that are suitable for planting. For instance, hybrid poplars, certain grasses and Indian mustard absorb heavy metals, while cattails and rice are able to neutralize organic compounds. ${ }^{61}$ Remediation can thus serve as a demonstration, showing the public aspects of the urban environment that would otherwise be hidden. These revelations enable the architecture

\footnotetext{
${ }^{59}$ Niall Kirkwood, ed. Manufactured Sites. (New York: Spon Press, 2001) 35.

${ }^{60}$ Kirkwood 52.

${ }^{61}$ Introduction to Phytoremediation, Table 3-1 Phytoremediation Overview, page 15
} 
of remediation to expand its influence beyond the physical contamination of the site; the project becomes engaged in a broader discourse concerning sustainability in the postindustrial urban environment.

Conventional remediation methods have little capacity for demonstration: practices such as hauling and capping are generally illegible once complete. Contaminated soil is removed to another site, or hidden beneath a layer of concrete or asphalt. $^{62}$ Either way, the soil's potential for demonstrating its contamination is lost, as is the project's ability to demonstrate the act of remediation. Similarly, designs that call for the destruction of a site's existing infrastructure also inhibit demonstration, as the erased heritage of the site is no longer legible to the public. For brownfields to realise their potential for demonstration, the process of remediation must be implemented in a manner that communicates to the public; by making the intentions of the project clear, architecture is better able to engage the public in critical reflection. Emerging remediation technologies, such as phytoremediation, offer greater demonstrative potential; these methods are able to elucidate the transformative act of healing. Phytoremediation involves the use of specially selected plants to treat contaminated soil. These plants can function as decontaminants by either neutralising the toxins within the soil, or by drawing pollutants into the roots and up into the shoots. Both strategies enable more contaminated soil to remain in place, until it is 'healed', thereby reducing - or even eliminating- the need for hauling and capping. Compared to conventional practices, phytoremediation is a relatively slow process; some cycles require decades to achieve completion. The longer period of time that it requires, however, enhances its capacity to demonstrate. While conventional decontamination

${ }^{62}$ Kirkwood 52 
strategies are fast enough to be completed prior to development, the extended period required by phytoremediation encourages the integration of remediation into the use of the project. This integration allows architecture to demonstrate the process of remediation to the public, rather than hiding it, as conventional methods do. As opposed to quickly completing all possible decontamination prior to development and use, projects incorporating phytoremediation are able to engage the public in a sustained demonstration of the process of healing the site. Phytoremediation can be construed as a monstrous metamorphosis; the transformation of contaminated land provokes critical reflection concerning the consequences of unsustainable development.

The use of plants central to phytoremediation is itself monstrous, as it challenges conventional delineations between nature and technology. As the "manipulation of natural processes to enhance contaminant removal from the environment, phytoremediation represents the unlikely conjunction of 'natural' vegetation with 'artificial' technology. In addition to its metamorphic qualities, phytoremediation is also a monstrous hybrid of advanced technology and primordial biological processes. The dichotomous opposition between nature and technology is further questioned by the introduction of genetic engineering. Currently, the plants used in phytoremediation are mostly species that have been selected for their existing abilities; advances in genetic engineering, however, have enabled scientists to isolate and artificially exaggerate these advantageous traits. ${ }^{64}$ These modified varieties of phytoremediators are poised to predominate in brownfield applications; their prevalence can also serve as a demonstration of the interconnectedness of society with the environment.

\footnotetext{
${ }^{63}$ Dzantor, Kudzo 77

${ }^{64}$ Dzantor, Kudzo 82
} 
Another aspect of these emerging technologies that challenges conventional delineations is phytomining, a process that involves the extraction of metals from contaminated soil, for collection and recycling. Plants that are especially efficient at this process are known as hyperaccumulators; the concentrations of heavy metals in their dried leaves can approach those found in commercially mined ores. Indian Mustard and Sunflowers, for instance, are especially well-suited for the extraction of lead. ${ }^{65}$ Crops of these and other similar plants are sent to smelters where the metals are recovered and recycled. This 'harvest' of metals from contaminated soil confuses definitions of mining and agriculture; the ambiguity of the situation is furthered by the urban setting common to most brownfields. As a monstrous hybrid combining mining, agriculture and decontamination in the city, phytomining demonstrates the permeability of the boundaries separating nature from artifice.

By architecturally emphasising the themes of metamorphosis and hybridism, designs involving phytoremediation can challenge delineations between nature and artifice. These themes imbue the act of healing with a monstrous quality that furthers its ability to engage the public in critical reflection. By demonstrating the indeterminacy of the relationship between human technology and nature, phytoremediation is able to provoke reconsideration of the impacts of unsustainable urbanism, while nurturing a sense of place. The act of healing thus extends beyond the specific site of contamination, to include support for the development of a public spirit of ecological and social responsibility.

\footnotetext{
${ }^{65}$ Kirkwood, 55.
} 


\subsection{Case Study: Landschaft Park Duisburg-Nord, Duisburg, Germany}

While there are many cases of toxic sites being restored to public use, few of these are allowed to retain much evidence of their former industrial lives, or of the processes required to make them safe. The decaying relics of the past are often dismissed as unattractive or otherwise undesirable, and are accordingly removed from the site. Similarly, soil treatment, by remediation or not, generally occurs prior to development, and is not incorporated into the new design. Thus, in many cases, what is returned to the public bears few if any traces of its history, and the process of remediation is concealed. The power of the site to demonstrate is denied. An exception to this convention is Latz + Partners' Landschaftpark Duisburg Nord, a project that demonstrates the pertinence of monstrous themes to the architecture of remediation.

Described by critic Hugh Hardy as "almost the ideal reuse of an industrial site,",66 the project has won multiple awards, while generating increased interest in both brownfield remediation and the preservation of industrial architecture. Located in the State of North Rhine-Westphalia, in North-Eastern Germany, Landschaftpark Duisburg Nord is part of the larger IBA Emscher Park. The winning entry from an international competition, Peter Latz's design encompasses 230 hectares of abandoned industrial buildings and brownfields. Not only does the design reveal and celebrate elements from the site's industrial past, it also allows the public to witness, understand and participate in the process of remediation. The project is a demonstration, one that enhances the site's genius loci by acting as a "vehicle of collective memory."

\footnotetext{
${ }^{66}$ Hugh Hardy. "The Romance of Abandonment: Industrial Parks" Places 17 no3 (Fall 2005) 35.

${ }^{67}$ Matthew Jelacic. "Arch Intimacy” Extreme Sites: the Greening of Brownfields 61
} 
One of Western Europe's most heavily industrialized regions, Duisburg-Nord's setting is one of severe ecological devastation. The Ruhr region endured over a century of heavy industrial activity, mainly involving the production of coal, iron, steel and related products. An emphasis on production began to pervade the region's identity; as Deborah Gans states:

This shifting ground of employment subjected the region's initially mixed society of agriculture, steel and commerce to an increasingly focused idea of labour, of 'inhabitants who put their lives at the service of progress' and moved along with it from worker settlement to worker settlement. ${ }^{68}$

With the gradual demise of heavy industries in the second half of the twentieth century, Duisburg suffered substantial economic and cultural decline. While prosperity and status were lost, the environmental legacy of the industries remained. Peter Latz describes the results as "a bizarre landscape: spaces torn to pieces and environmental damage, land settlement with swamps and polders, slag heaps instead of flood-plain forests and soils polluted with polyaromatic hydrocarbons and heavy metals."69 The competition offered an opportunity to improve both the ecology and economy of the region, enabling "the reanimation of the devastated areas and their regeneration as a landscape for a densely populated territory."70

Inherent in Peter Latz's design is a recognition that the landscape's significance extends beyond ecological and economic considerations, to include less tangible concerns as well. With the decline of heavy industry in the decades following the Second World War, the Ruhr district also experienced "social change and a loss of cultural significance

\footnotetext{
${ }^{68}$ Deborah Gans. "The Sky Above and the Ground Below Emscher" Extreme Sites: the Greening of Brownfields. 52

${ }^{69}$ Kirkwood 150.

${ }^{70}$ Kirkwood 150.
} 
in the region."71 Regional identities had long been intertwined with the dominance of production and heavy industry; its loss precipitated a diminishment in the local population's pride of place. Latz's design seeks to restore local pride by reinforcing the site's genius loci. To do so, Landschaft Park Duisburg-Nord celebrates the land's industrial past, exhibiting "an aesthetic of gigantic objects that could potentially function as landmarks and nourish the genius loci of the site."72 Rather than erase or disguise Duisburg-Nord's heritage, Latz integrates the remnants of heavy industry into his design, granting them new uses and celebrating their presence in the landscape. These remains undergo a metamorphosis, demonstrating "a new regard for industrial heritage as a potential for cultural identification., ${ }^{, 73}$ The new uses granted to these remnants enable them to act as demonstrations of the site's reanimation; by imbuing Duisburg Nord with new life, Latz's design resists the fixity of conventional heritage preservation.

Peter Latz uses the unusual forms of the site to create opportunities for recreational activities found in few other urban parks, enriching the site's mix of visitors while enhancing its sense of place. One case of this type of metamorphosis is the Gasometer, "a former gas tank that has been filled with water and is now the world's largest indoor diving center."74 Latz attributes these transformations to a design philosophy that respects industrial heritage:

Instead of building objects for specific uses, fantasy and playfulness allow existing abstract structures to function in new ways. Thus our working method is one of adaptation and interpretation, a metamorphosis of industrial structures without destroying them. $^{75}$

\footnotetext{
${ }^{71}$ Judith Stilgenbauer. "Landschaftspark Duisburg Nord - Duisburg, Germany" Places 17 no3 (Fall 2005) 6.

${ }^{72}$ Stilgenbauer 7.

${ }^{73}$ Peter Zloniky, "Strategies for Extreme Conditions: the Emscher Park International Building Exhibition" Extreme Sites: The 'Greening' of Brownfield ( 60

${ }^{74}$ Stilgenbauer 8.

${ }^{75}$ Kirkwood 151.
} 
Flooded by ground water, subterranean ore bunkers are also open to local scuba enthusiasts. The divers are actively engaged in remediating the site as they "remove impurities and rubbish, and search for adventure in the dark corridors"

An old blast furnace is also transformed, becoming "a menacing 'dragon' frightening men and rising above its surroundings, ${ }^{, 77}$ while simultaneously acting as a pinnacle for mountain climbers. Other opportunities for climbing are found in the ore bunker walls, the concrete of which has been scarred by industrial processes. These scars serve as hand and foot holds for free-climbers, creating a very direct and tactile connection between the site's current recreational use and its former industrial life. This tension between the industrial past and recreational present imbues the project with a monstrous quality, one that enhances its ability to act as a critique of the excesses of modernity.

The Piazza Metallica also employs metamorphosis in order to enhance the site's genius loci. The plaza, "situated at the symbolic heart of the park, serves as its central event and gathering space" ${ }^{, 78}$ and features 49 recycled iron plates, arranged in a square at the space's center. These plates, found at a nearby pig-iron casting works, are intended to symbolize the transformation of decaying industrial infrastructure into a public park. The idea of metamorphosis is expressed by the plates' visual reference to their molten past: "melting and hardening was to be simulated by water flowing and settling on the surfaces." ${ }^{, 79}$ As Latz describes, their meaning lies in their changing texture:

\footnotetext{
${ }^{76}$ Kirkwood 151.

${ }^{77}$ Stilgenbauer 7.

${ }^{78}$ Stilgenbauer 8 .

${ }^{79}$ Kirkwood 150.
} 
Cleaned of ashes and of casting sediments, they revealed their subtle patterns: ice and iron in a shimmering square during rainfall. 'Physical nature' becomes a symbolic theme. From the first moments of their existence, these plates are eroded by natural physical processes. In this new place, they will continue to rust and erode. ${ }^{80}$

The plates recall their own industrial origins, and by extension, that of their setting. By referencing a layer of the site's history, Latz is able to enhance its genius loci, reinforcing both the Piazza Metallica's role within the hierarchy of the park, and the park's significance to the region. Latz's use of the plates imbues them with a monstrous quality: their implied metamorphosis integrates the site's current recreational life to its industrial past, thereby blurring temporal delineations. Metamorphosis is also conveyed through means other than the application of new uses; materiality and tectonics are also used to demonstrate the transformation of the site. In some instances, new pathways require cuts to be made in the existing walls; elsewhere, the ground is "brightly coloured by recycled brick chippings. ${ }^{, 81}$

\footnotetext{
${ }^{80}$ Kirkwood 151.

${ }^{81}$ Kirkwood 157.
} 


\subsection{Point Saint-Charles and the Grand Trunk Railway Shops}

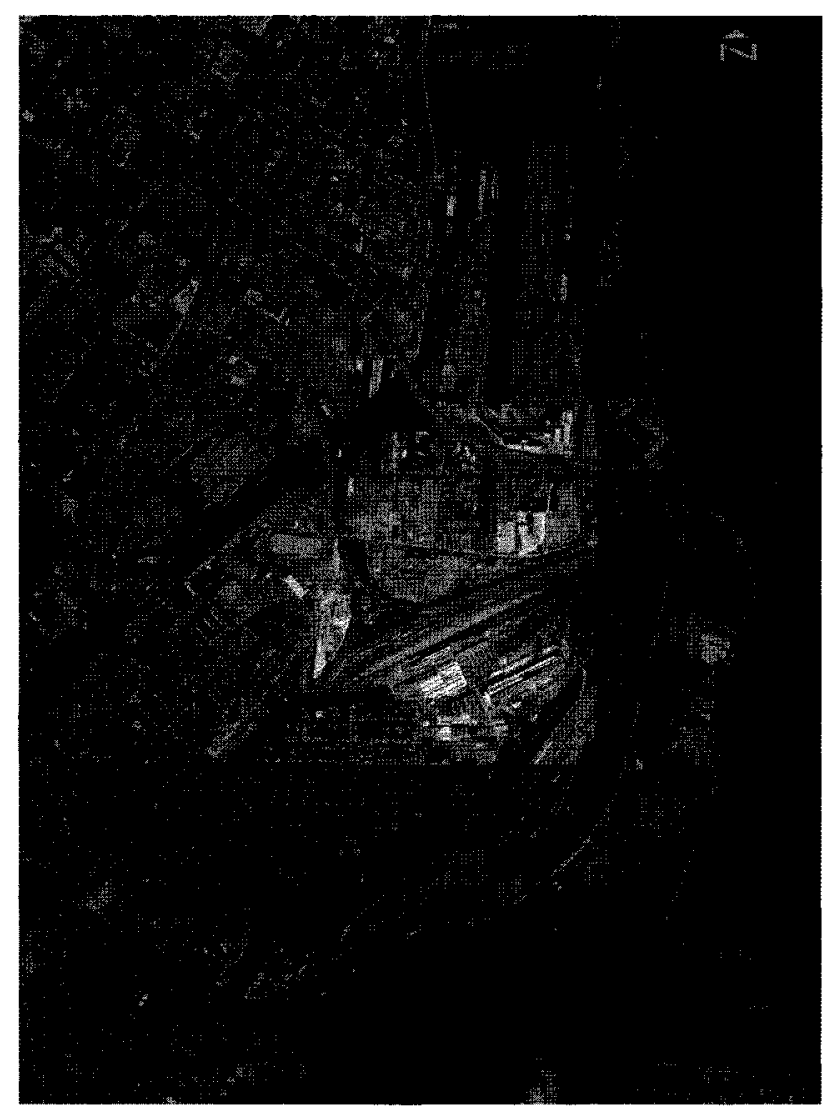

Figure 1: Aerial Photograph of Point Saint-Charles The neighbourhood of Point-Saint Charles is dominated by the vacant yards of CN's shops. Montreal's core and the Old Port are seen at the top-left of the image.
The neighbourhood of Point

Charles embodies many of the issues

facing the post-industrial urban

environment. Immediately southeast of downtown Montreal, the area is a mixture of light industrial and low- to middle-income residential uses, with an abundance of vacant land and abandoned buildings. It is surrounded and bisected by the paths of multiple regional and continental transportation networks, and at its heart lies the yards and shops of the Grand Trunk Railway. Despite the visibility afforded to the area by the transportation infrastructure and its proximity to the city's core, Point SaintCharles remains on the periphery of Montreal's urban consciousness.

Earlier in the neighbourhood's history, however, the status of Point Saint-Charles was anything but marginal. Its rise to prominence was fuelled by the construction of major works of transportation infrastructure, the first being the Lachine Canal. Bypassing the Lachine Rapids, the canal's construction reinforced Montreal's status as one of the most strategically situated cities in North America: before the advent of 
railways, the Lachine Canal served as the only practical Canadian link between the outside world and the continent's interior. To borrow the words of architect Pieter Sijpkes, the Lachine Canal was the nation's "watery umbilical cord." 82 Initially completed in 1825 , the canal was twice enlarged to accommodate the growing demands of industry and commerce. The canal's construction and subsequent enlargements required thousands of workers, many of whom remained in the area after the project's completion. Those who stayed found employment in what quickly became the "cradle of Canada's manufacturing industry." ${ }^{83}$ While these workers were themselves socially and economically marginalised, where they worked was not: Point St.-Charles was recognised as being the leader of the nation's nascent industrial economy.

In the late 1840 s, the new railways began to eclipse the canal in importance as a transportation link; Point Saint-Charles, however, retained its image of being at the forefront of Canadian productivity and engineering. The new railways contributed greatly to the construction of this modern identity, with the Victoria Bridge playing a leading role. Opened in 1859, the cast iron bridge connects Saint-Lambert on the south shore of the St. Lawrence to Point Saint-Charles and Montreal. Widely promoted as "the eighth wonder of the world," the structure featured prominently on many postcards in the late $19^{\text {th }}$ century ${ }^{84}$ In addition to advancing Montreal's image as 'Canada's Metropolis,' the Victoria Bridge also brought further industrial investment to Point Saint-Charles, such as the Grand Trunk Railways' shops and yards.

\footnotetext{
${ }^{82}$ Demchinsky 179.

${ }^{83}$ Lachine CD ROM, Ville de Montréal

${ }^{84}$ The Victoria Bridge: Eigth Wonder of the Modern World http://www.mccordmuseum.qc.ca/en/keys/virtualexhibits/victoriabridge/
} 
While new transportation infrastructure initially brought increased activity to Point Saint-Charles, it later took it away. During the 1960s, many of the businesses operating in the neighbourhood closed; the subsequently high rate of unemployment forced many residents to leave. Over the next generation, the population of Point SaintCharles fell from a peak of 35,000 to $13,000 .{ }^{85}$ Two new pieces of transportation infrastructure contributed to the industrial decline: the St.-Lawrence Seaway and the new expressways.

During the later half of the twentieth century, the site was occasionally considered for redevelopment, yet none of the proposals was implemented and the yards and shops remain vacant. Currently, the city is projecting that the area will eventually be occupied by a large convention centre, which will facilitate Point Saint-Charles' integration into the city's core. Unlike precedents such as Autoroute Ville-Marie and Place Radio Canada, which removed and replaced sections of the urban fabric, the city intends to retain aspects of the area's heritage; the change brought by redevelopment will be one of transformation rather than replacement. Similarly, for the redevelopment to be of the greatest value to the city, the decontamination strategy must transform the soil, instead of removing it from the site. The process of remediation proposed in this thesis is informed by the concept of metamorphosis.

\footnotetext{
${ }^{85}$ Sijpkes, 184
} 


\subsection{The Monstrous Recreational Centre}

The design employs the concept of monstrosity as a means of demonstrating the ambiguous but pervasive role that technology plays in the urban environment, as well as the similar relationship it shares with human corporeality. To develop these themes, the design proposes an architecture and integrated landscape of remediation of a contaminated property in Point Saint-Charles, Montreal. Immediately southwest of the city's core and the Old Port, the site is (un)occupied by abandoned rail yards and shops, which at their peak employed over seven thousand nearby residents. The proposal details the reuse of the facility's power generation building, within the framework of a larger phytoremediation and urban revitalization strategy. The building itself is converted into a community recreation centre, while short-term residential units are proposed for above the neighbouring assembly hall. The design is guided by the intention of revealing the indeterminacy of the boundaries between nature and artifice; this demonstration is argued to encourage critical reflection of post-industrial urban life.

Challenging these boundaries, the intervention is conceived as the reanimation of the decaying factory; like Frankenstein's creation, the building's new body is stitched together from the remnants of others, the seams demonstrating the architecture's monstrous origins. Unlike conventional approaches to heritage architecture, which tend to emphasise restoration or preservation, this thesis is developed using the inherently less static strategy of metamorphosis. To demonstrate this transformation, the recreational centre acts as a grotesque body: "never finished, never completed; it is continually built, continually created." ${ }^{86}$ Legibly dynamic, the intervention resists the immutability of

\footnotetext{
${ }^{86}$ Frascari 32.
} 
completion and permanence, challenging axiomatic conceptions of civic structures and the sanctity of heritage architecture. Similarly, the design resists neoclassical conceptions of corporeality; the body of the recreational centre is conceived as a dynamic system of organs, their tissues filtering the water that passes through the building. Rather than emphasising exteriority through the static perfection of an impenetrable skin, the intervention instead demonstrates the process of remediation by revealing its dynamic inner workings.

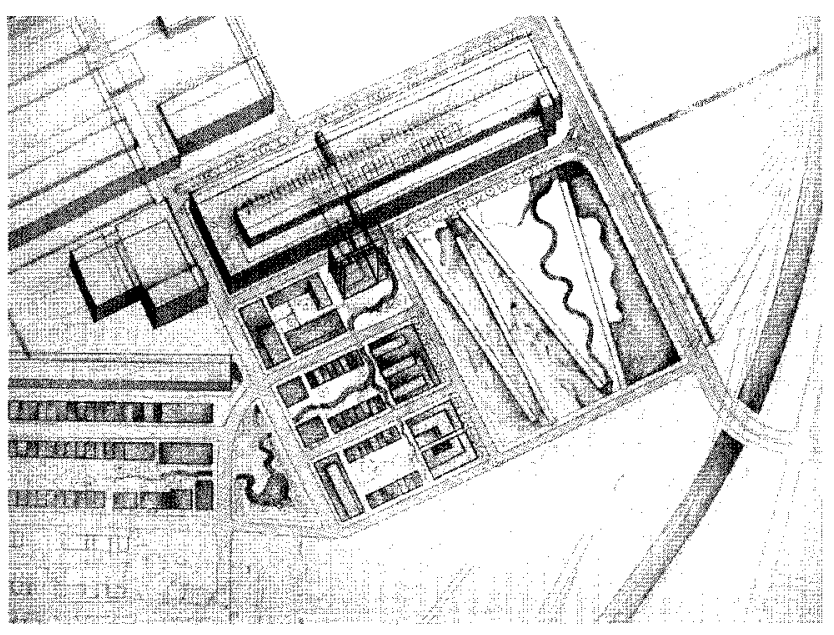

Figure 2: Detail of Site Plan

Water draining from the roofs of neighbouring buildings and surrounding landscape filters through the recreation centre. It then irrigates the constructed wetland and phytoremediation crops, before entering the SaintLawrence River.
The process of remediation, which will take decades, is one that will change form over time. As the soil becomes tolerable to a greater variety of plant species, new ones are introduced. This process of directed diversification demonstrates the healing of the site, while increasing the variety of toxins that can be absorbed.

Similarly, the path of water circulating through the site is exposed, revealing its central role in the remediation effort. As rainwater drains from the roof of the neighbouring building, it passes visibly through the recreation centre. Filtering through multiple passages and pools until it is finally drained into the surrounding landscape, the water then irrigates the phytoremediation fields and constructed wetlands. Its continual movement through the site shows the dynamic nature of the remediation process; the water's ever-changing state is a demonstration of the site's metamorphosis. The 
exposure of the water's path, which moves unexpectedly between the interior and exterior of the building, also relates to the concept of the grotesque body, as "the outward and inward details are merged." ${ }^{87}$ By deliberately confusing the two, the design exposes the healing process, while acting as a monstrous challenge to ideas of interiority and exteriority. This challenge provokes critical reflection of the experience of architectural space, as well as reconsideration of the limits of corporeality.
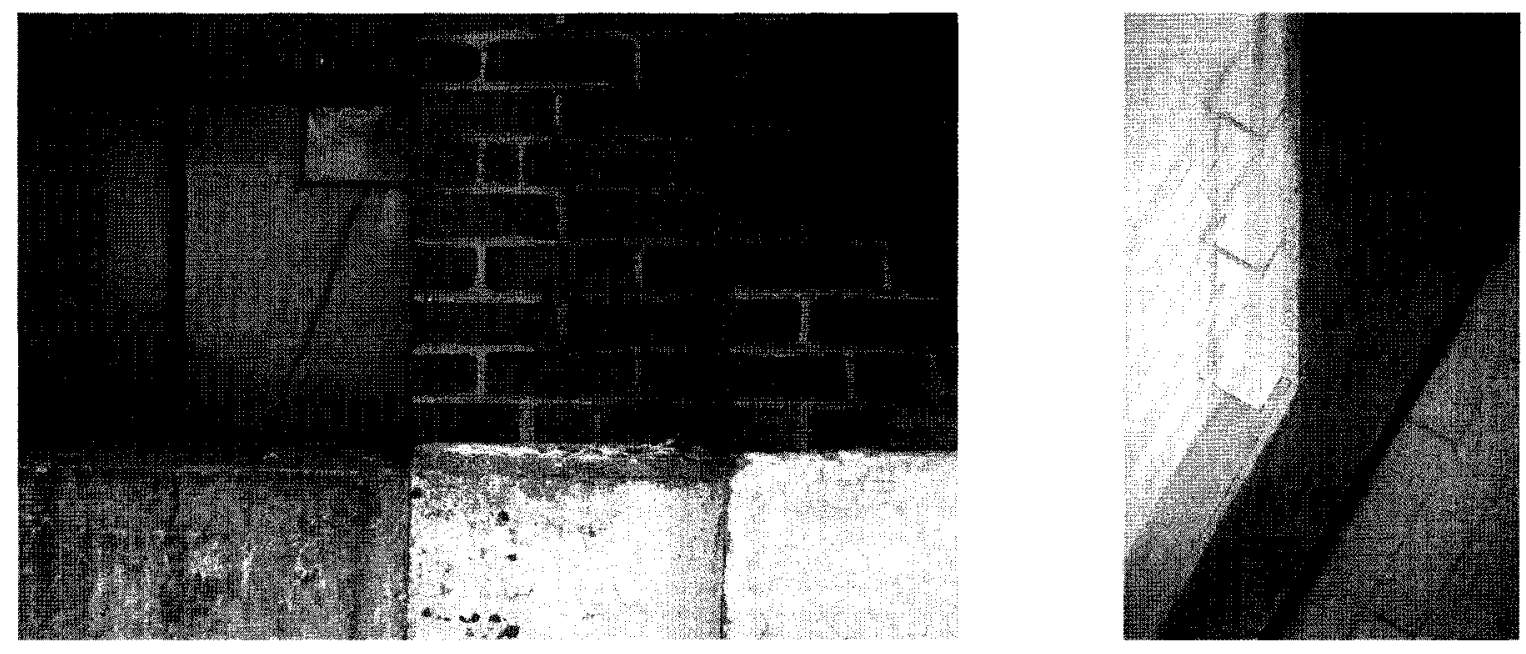

\section{Figures 3 and 4}

The fixed boundary of the existing façade, on the left, becomes a porous and malleable skin, on the right.

Boundaries defining interiority and exteriority are further challenged by the building's new envelope, which resists the static predictability of its predecessor. The existing envelope is dominated by regularly spaced plate-glass windows set between load-bearing brick and concrete walls; together they define the incontrovertible limits of the building. Similar to neoclassical ideals of corporeality, the existing envelope emphasises the completion and perfection of an impenetrable surface. Drawing inspiration from the concept of the grotesque body, the building's new skin resists the boundaries set by its predecessor, while emphasising porosity and metamorphosis. The

\footnotetext{
${ }^{87}$ Frascari 32.
} 
building's skin is pulled forward on the east and north façades, creating space for a new entry and circulation elements. When viewed from these sides, the new skin reads as a permeable membrane protecting the sensitive organs within. On the sunnier south and west façades, the new glazing is set behind the wall; this added depth enhances its transformation by shadows during the day, while creating the impression of an internally lit skeleton at night.

The building's newly displaced skin also demonstrates metamorphosis through its materiality and assembly. To provide shade for roof top terraces, railway ties salvaged from the yard are given new life as operable louvers. Their movement animates the building's skin throughout the day, imbuing its surface with changing degrees of penetrability. Facing the park, trellises constructed from recycled metal fencing provide

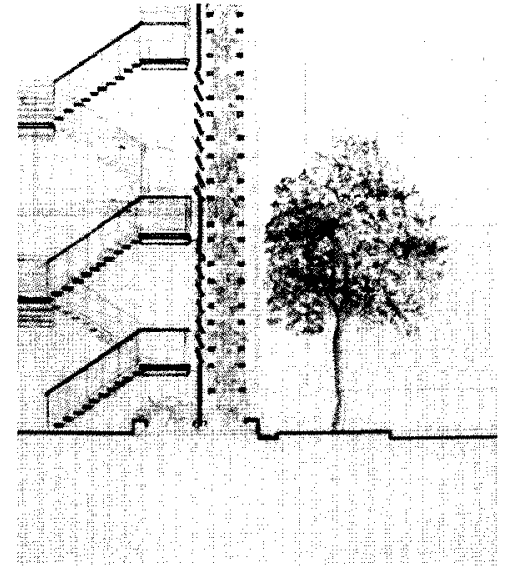

Figure 5: Section Through Trellis

Facing the park, trellises made from recycled chain-link fencing provide support for climbing vines. support for another dynamic layer of the building's skin: climbing vines. The cyclical qualities of their foliage demonstrate seasonal variations by transforming the texture and opacity of the building's skin, while their integration into the wall assembly blurs distinctions between nature and artifice. Elsewhere, the glazing itself is also designed to demonstrate metamorphosis: angled slightly, it carries water flowing off the roof during rain; with precipitation, the glass appears to be transformed into rippling sheet of water. The joints between the new skin and the existing structure are detailed to enhance its metamorphic character; in places the skin seems to grow from 
within the existing structure, while elsewhere it appears as a membrane stretched taut over the old masonry.

Just as the exterior of the building is thought of as a skin, the industrial machinery inside is conceived as its organs. Corporeally, the recreation centre consumes, digests and excretes. As in the surrounding landscape, the design emphasises the passage of water through the building's systems; its movement and transformation are felt throughout. After circulating through the pools and channels on the roof, the water is drained into the coal trough, the large suspended metal vessel at the southern end of the engine room. Here, in the recreational centre's liver, impurities are removed as the water

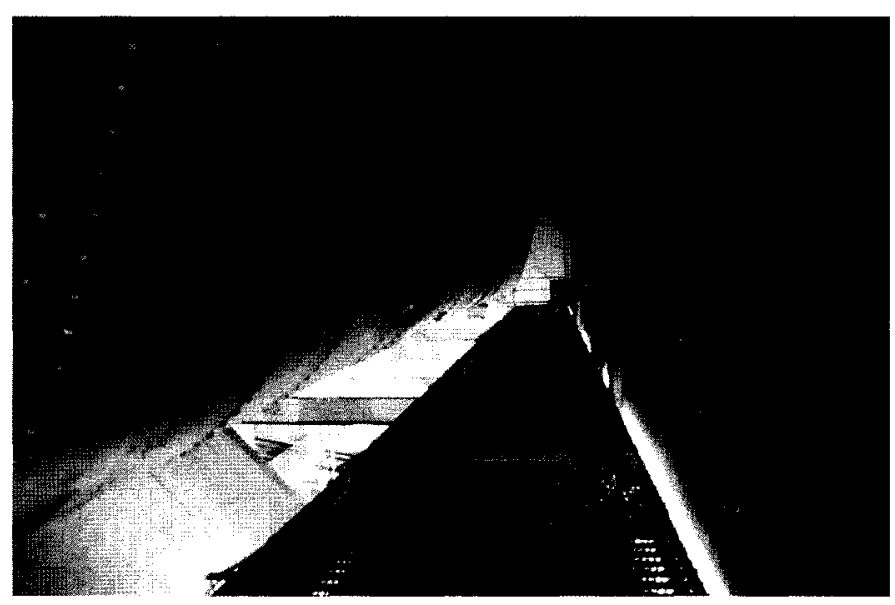

Figure 6: Photograph of Existing Coal Trough The existing coal trough, suspended over the southern end of the Engine Room.



Figure 7: Section Through Trough

The trough becomes the liver of the Recreation Centre's system of organs.

flows through a series of salvaged tanks, each inhabited by different varieties of vegetation. These plants absorb organic pollutants, filtering the water so it can be recycled for use in the showers and change rooms below. Openings are cut in the sides of the trough, exposing the plants to sunlight while revealing the system of tanks; their significance is further emphasised by the presence of a path traversing the tank. 
Below the trough, the two furnaces are transformed into male and female change rooms, showers and saunas; these are construed as the left and right chambers of a heart. They are the warmest and most private of the reanimated building's organs. The water fuelling the two reaches down through recycled pipes from the nearby coal trough. On the top level where the pipes enter the furnaces, in the saunas, the metal roof is cut away and replaced with glass, revealing the view of the water's path, while allowing the entry

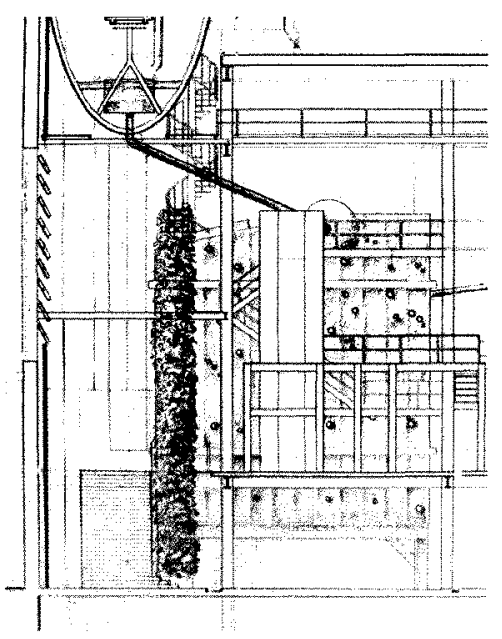

Figure 8: Elevation of Furnaces

The twin furnaces become the change rooms, saunas and spas of the recreation centre

Figure 9: Vignette Lenses salvaged from the dials of abandoned equipment become windows in the walls of the furnaces

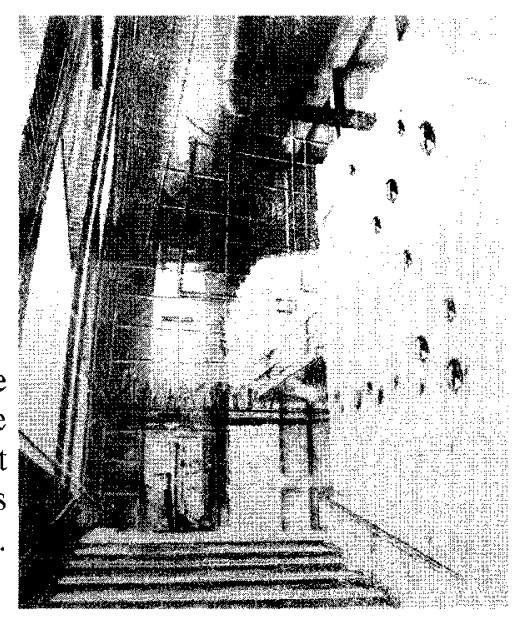

of natural light. To provide more light to the darker lower levels, variously sized glass lenses salvaged from the dials of obsolete equipment are reused as windows. From outside the chambers they recall bubbles, warts or eyes; when viewed from within they transform the walls of the furnaces into starry skies. To emphasise the monstrous qualities of the lenses, the surrounding metal panels are deformed: the detailing of the joint between window and wall suggests that the lenses are pushing out, stretching the skin of the chambers taut. This impression is furthered by the presence of similar openings without lenses, which allow steam to escape from the reanimated furnaces. The two appear as though bulging, their contents under pressure. Their skin is transformed into a demonstration of the heat and moisture within. 
In addition to consuming, digesting and excreting, the community recreational centre can also be construed as breathing. A tall green surface of plants constitutes the lung of the building; here water makes its presence felt indirectly through an abundance of lush foliage. While plants found elsewhere in the intervention absorb pollution through their roots, those inhabiting the wall do so through their leaves: through respiration, the plants purify the air. Monstrously, however, the building does not inhale or exhale through any solitary orifice; instead it depends on the gills of its porous skin. In addition to making the movement of air through the building more legible, this system of ventilation also blurs the boundaries between interior and exterior. On a hot summer day, for instance, much of the skin of the boiler room can be retracted, allowing breezes from the nearby St. Lawrence River to cool the interior.

Connectivity to the River is underscored by the geometry of the phytoremediation crops, whose irrigation channels lead water and the eye toward its banks. The Recreation Centre's local importance is emphasised by its privileged position on the water's path towards the River: most of the water draining from the neighbourhood passes through or near the building. Like the water draining from the roofs of other buildings in the defunct facility, water draining from new development is also treated by the Recreation Centre. Rather than being treated within building, however, this runoff and grey water is filtered by the constructed wetland in front. The design of the wetland emphasises metamorphosis through the creation of a variety of aquatic habitats; the changing state of water as it moves from one environment into the next demonstrates the filtering role played by the vegetation. 
In addition to being demonstrated by the water's changing state, the process of purification is also shown by the accumulation of dirt. Rather than being discarded as waste, impurities removed from the water are retained and celebrated. In places enjoying high visibility, water moving from one place to another is directed against an intermediary surface of porous concrete; over the years, stains appear, demonstrating the life and age of the building. These stains are monstrous; as anthropologist Mary Douglas remarks: "Reflection on dirt involves reflection on the relation of order to disorder, being to non-being, form to formlessness, life to death." ${ }^{88}$ Monstrously, dirt provokes critical reconsideration; in addition to demonstrating the process of purification, the Recreation Centre's stains simultaneously question conceptions of purity.

To reinforce the theme of metamorphosis, this thesis represents the intervention through collage. Like Frankenstein's monster and the proposed recreational centre, the representation of the intervention is a monstrous assembly of multiple media. In the plans and sections, the existing building is represented by computer-generated black lines, while the intervention is drawn by hand with coloured lead. Subtractions from the existing building are shown by obscuring the black lines with a thin layer of white correction fluid; the raised scar left on the surface of the paper provides a record of past construction, enhancing the demonstration of metamorphosis. Transformation is further conveyed by the application of transferred images; these suggest the proposed uses that will reanimate the building. Similarly, vignettes representing specific events within the intervention also employ collage; layered transfers of existing components are reassembled -stitched together by chalk rendering. These representations, like the design

\footnotetext{
${ }^{88}$ Mary Douglas. Purity and danger: an analysis of concepts of pollution and taboo. (London: Routledge \& K. Paul, 1966) 5.
} 
of the intervention itself, are conceived as surgical procedures. Their monstrous assembly blurs delineations between the hand-drawn and computer generated, echoing the challenges the design poses to distinctions between nature and artifice. 


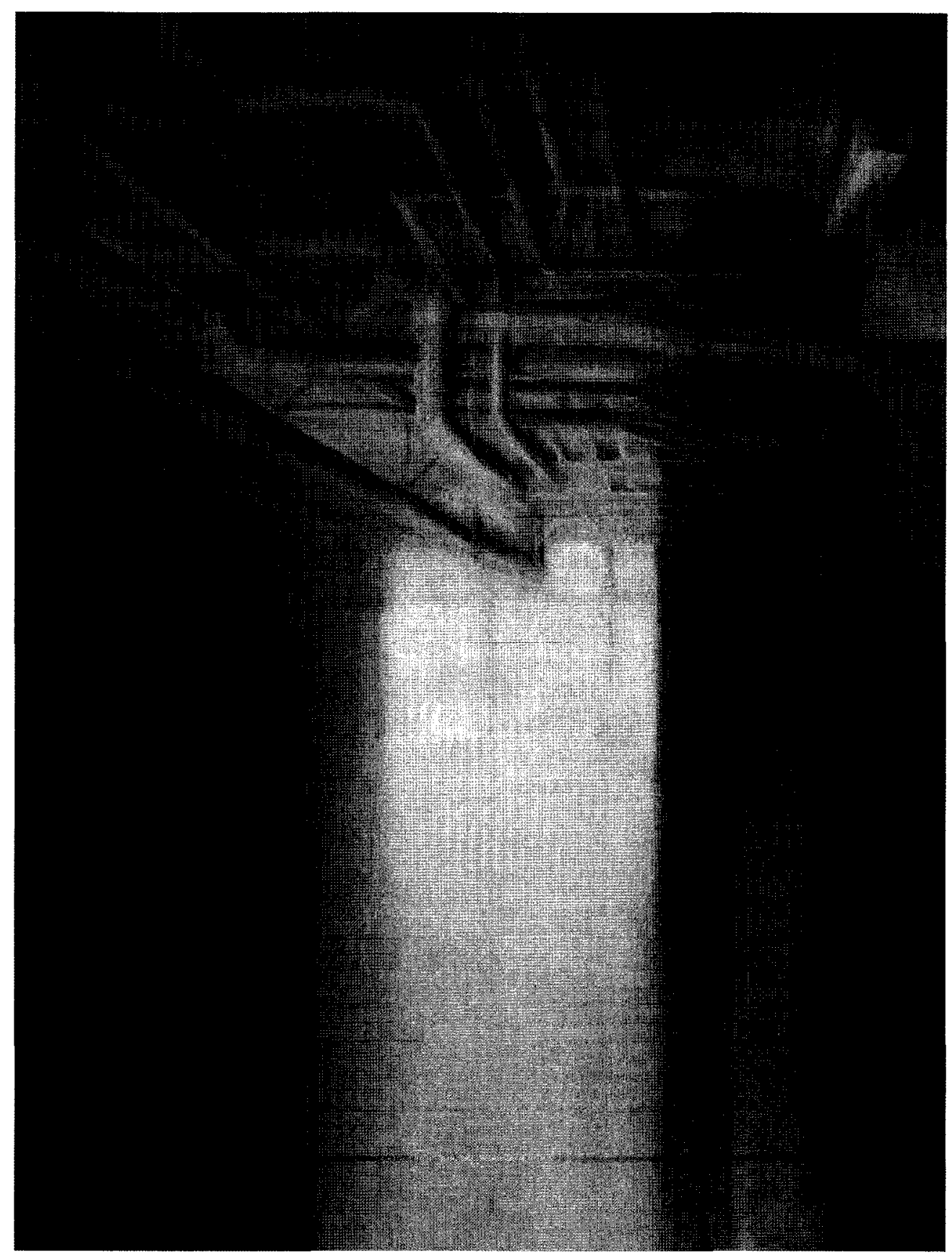

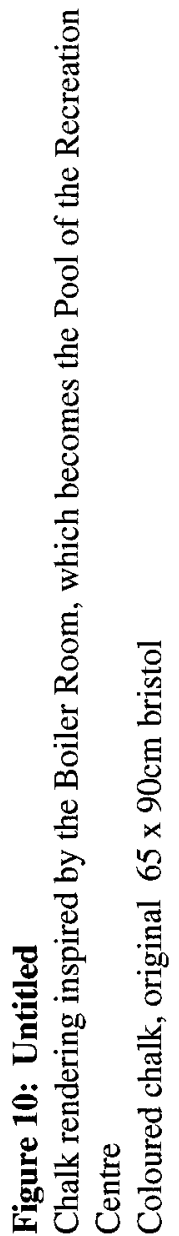




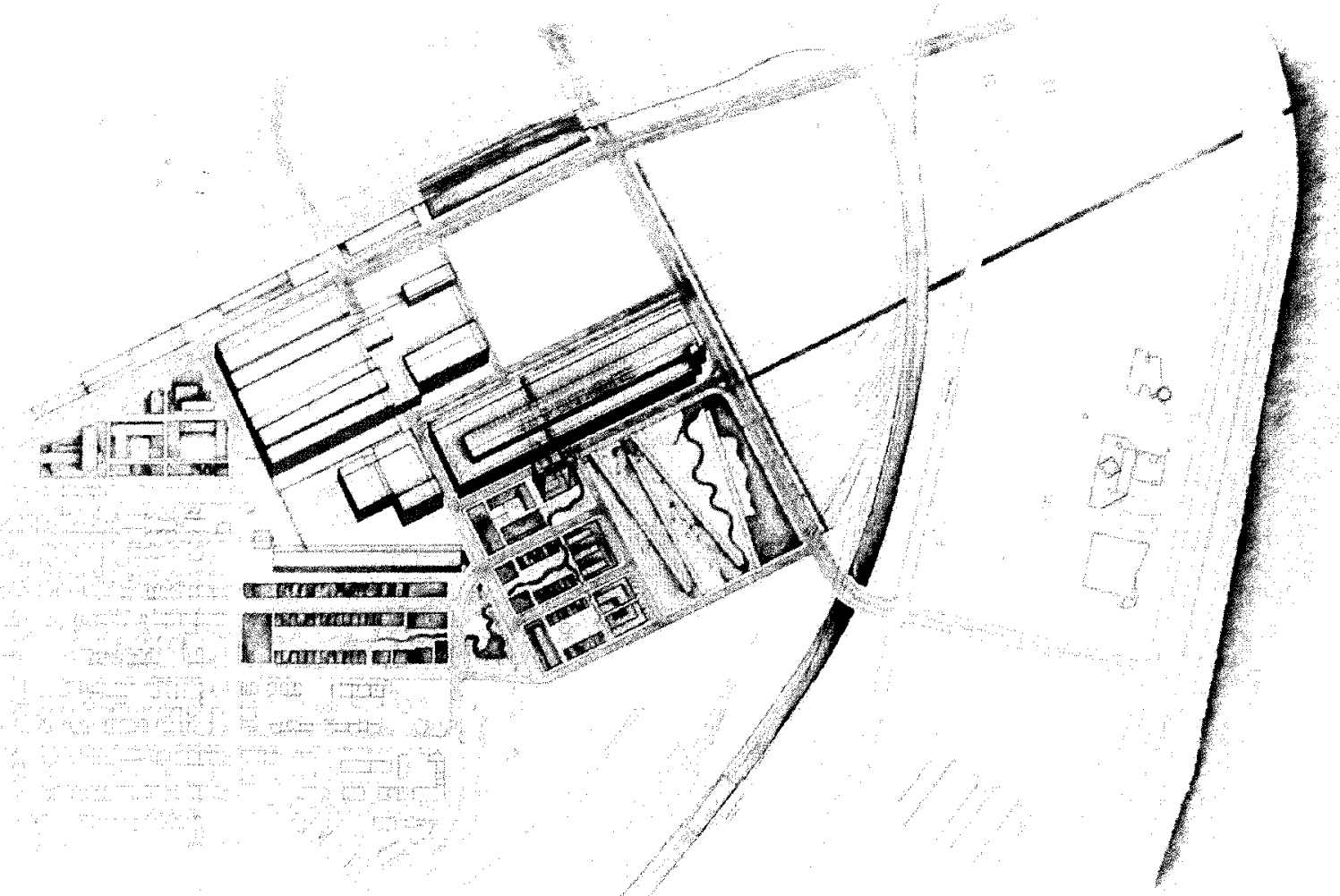

Figure 11: Site Plan of the rail yards at Point Saint-Charles:Water drains from the roofs of the larger buildings in the complex, passing through the recreation centre, the adjacent park and into the Saint Lawrence River.

Printed ink and collage with drawn lead and ink

Original 1:2000 on $76 \times 112 \mathrm{~cm}$ Stonhenge 







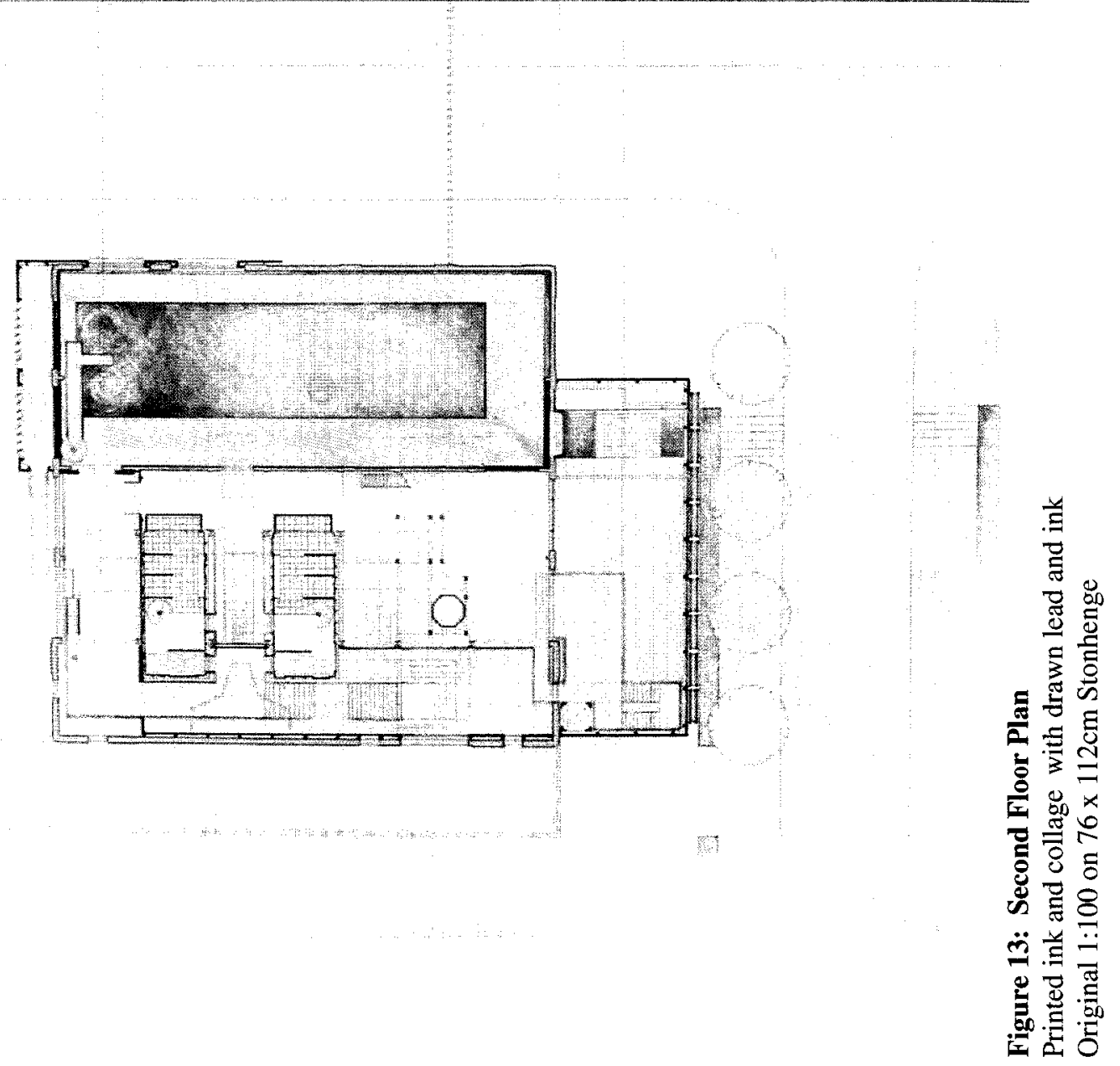




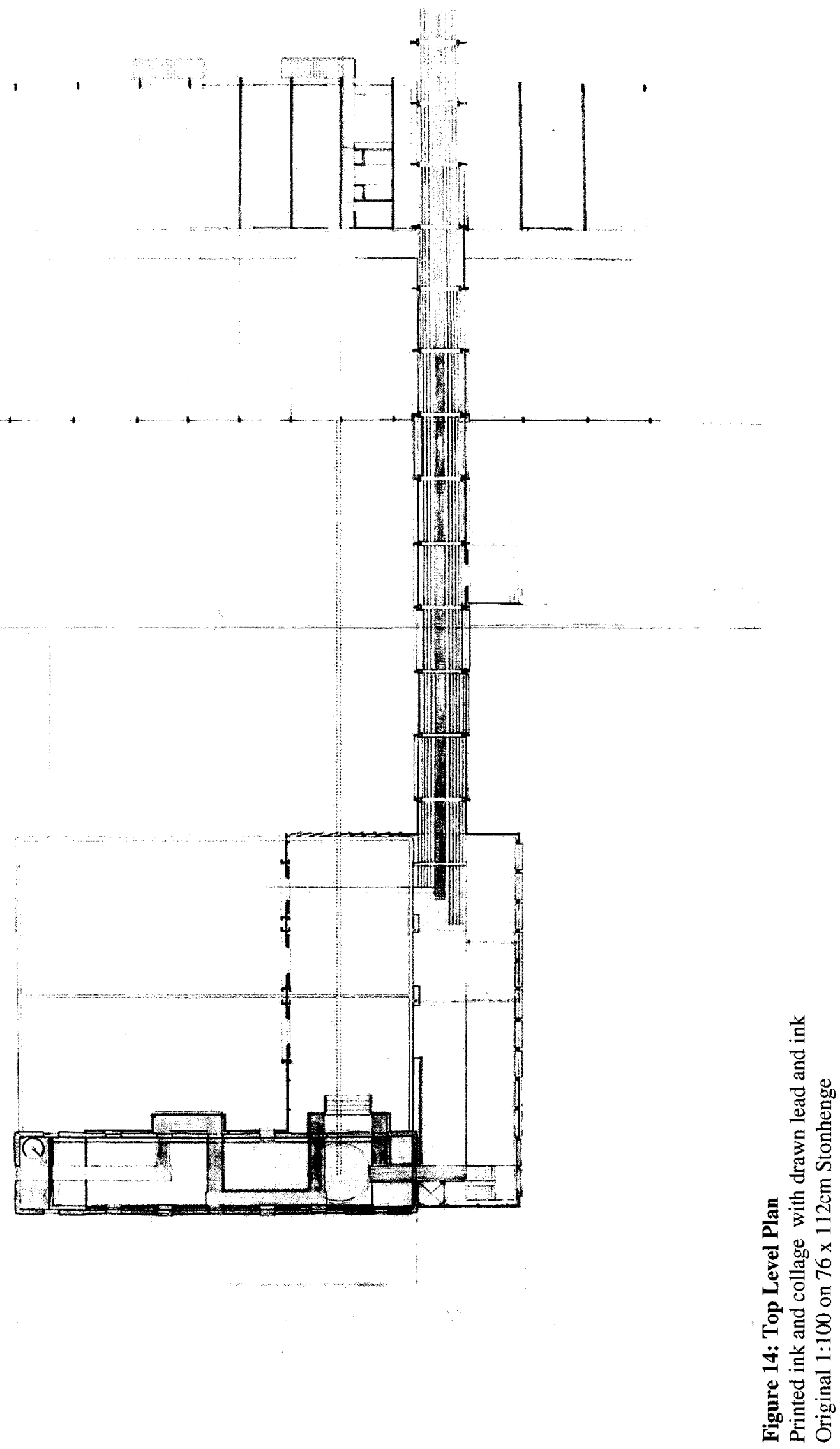




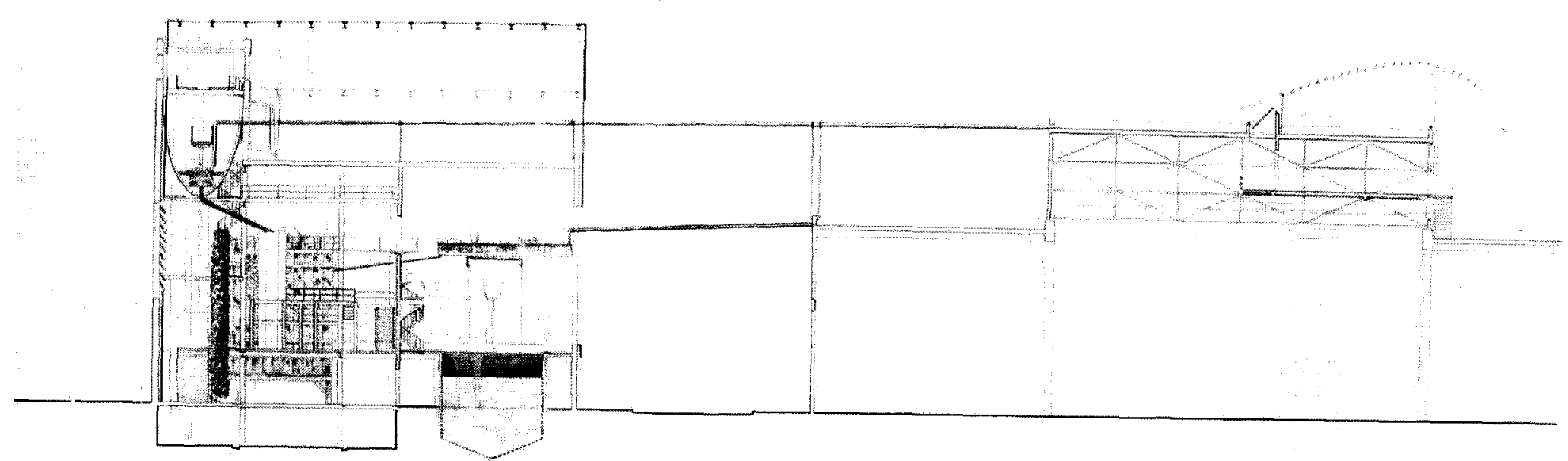

Figure 16: Section through Recreatioin Centre and Convention Centre showing the path of rainwater Printed ink and collage with drawn lead and ink

Original 1:100 on $76 \times 112 \mathrm{~cm}$ Stonhenge 


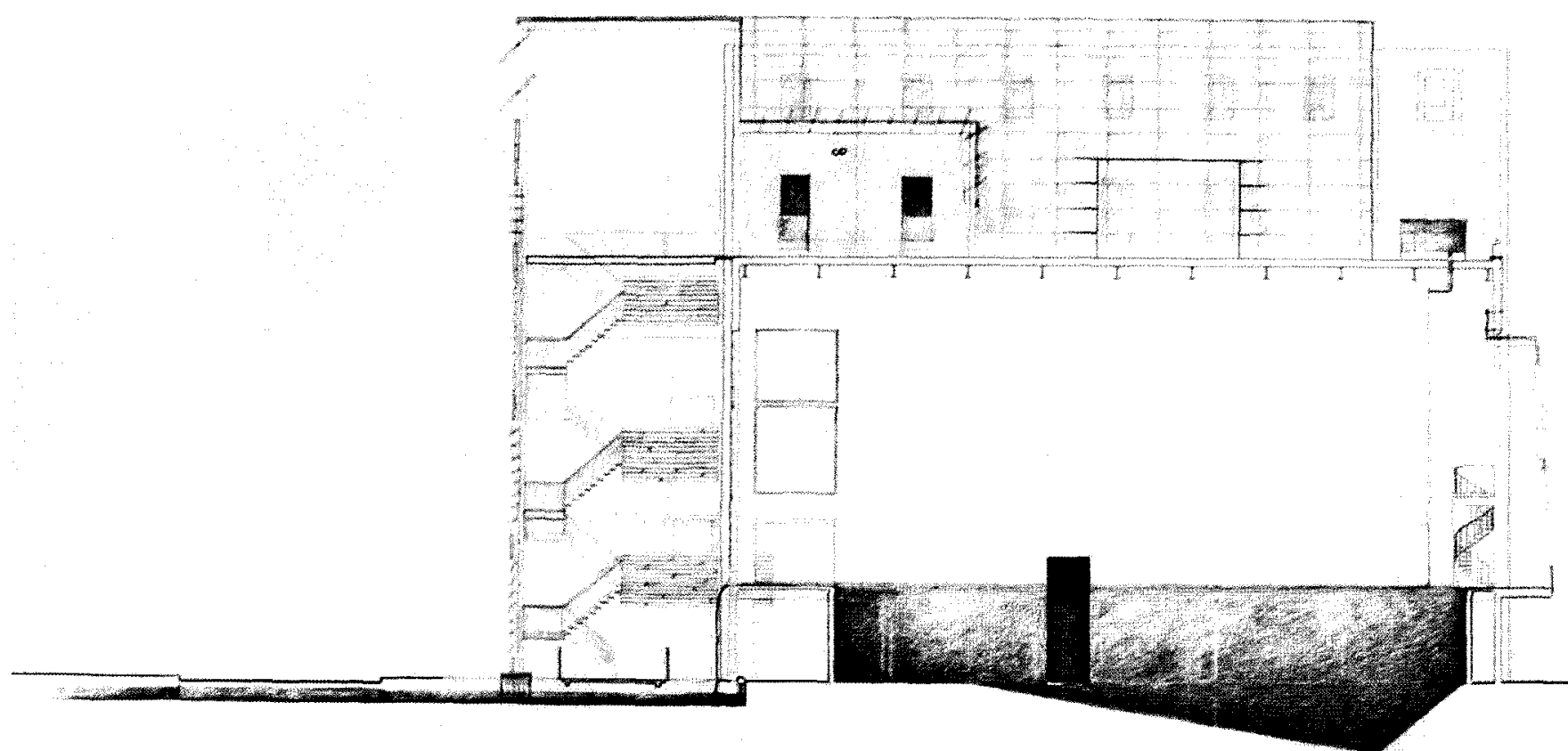

Figure 17: Section through Pool Room

Printed ink and collage with drawn lead and ink

Original 1:100 on $76 \times 112 \mathrm{~cm}$ Stonhenge 




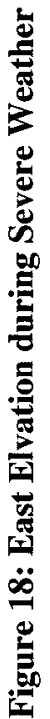




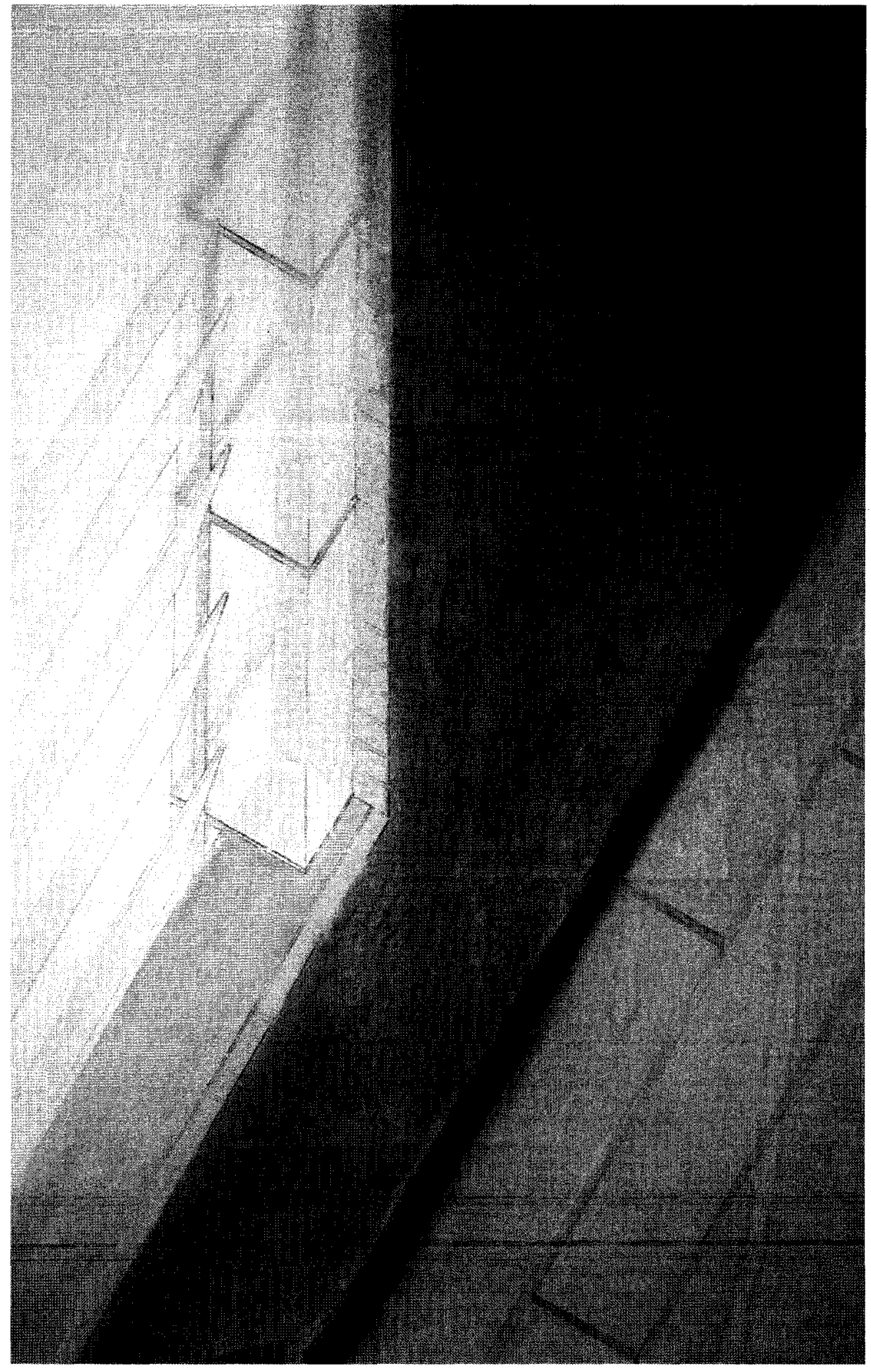

Figure 19: Axonometric Detail of connection between new window assembly and existing masonry in Pool (Boiler) Room.

Coloured chalk and acetone transfer Original 1:5 on $76 \times 112 \mathrm{~cm}$ Stonhenge 


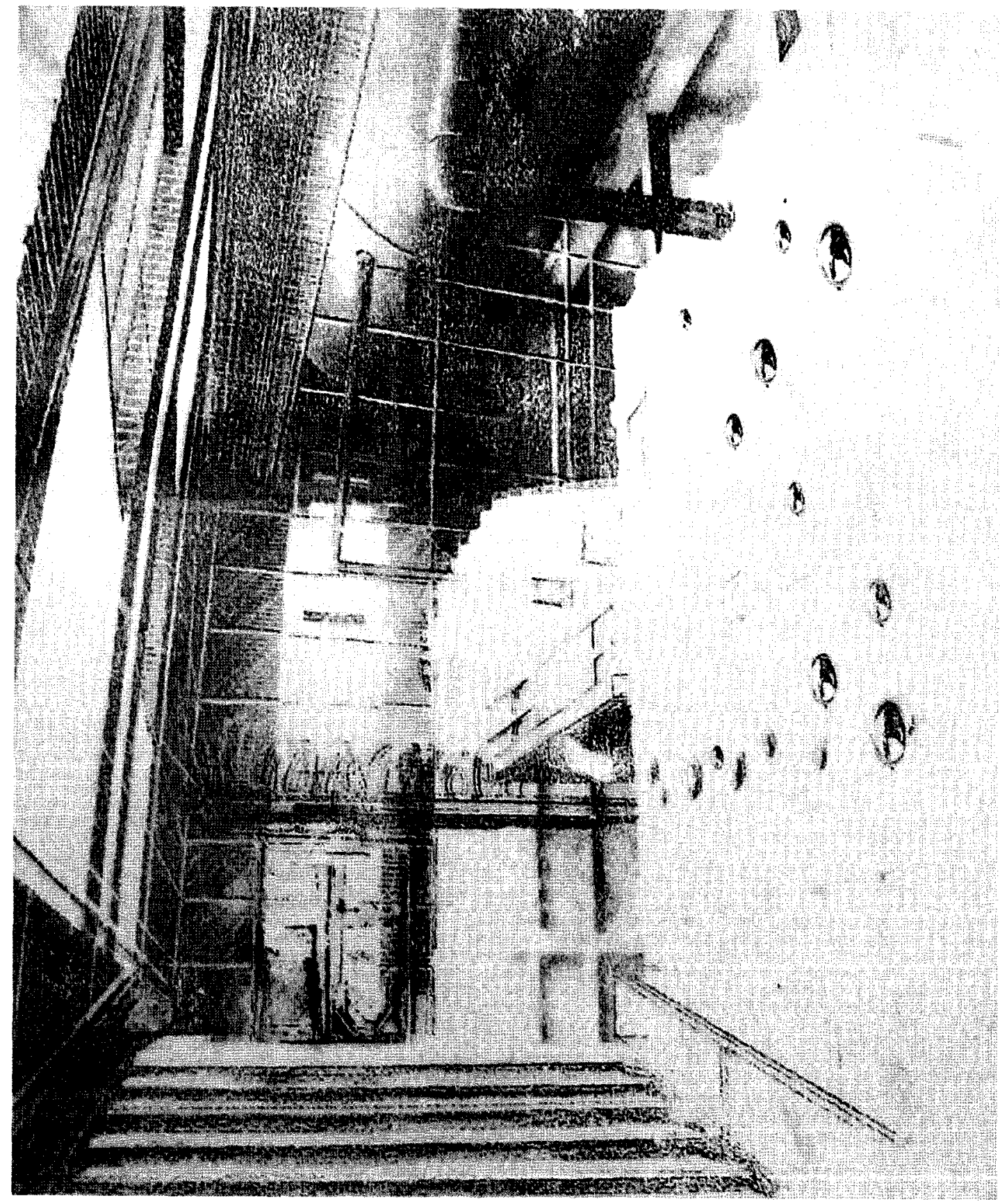

Figure 20: Vignette of Approach to Furnaces

Lenses salvaged from dials are reused as windows in the metal wall 


\section{$6.0 \quad$ CONCLUSION}

To challenge the dichotomous opposition between nature and artifice, the design demonstrates the process of remediation, employing the grotesque body as a guiding metonym. The architecture of brownfield remediation, when informed by the concept of monstrous corporeality, is able to further a critical understanding of the ambiguous but pervasive role that technology plays in the post-industrial city. This understanding is contended to extend the act of healing beyond the physical limits of the site, to foster a public spirit of environmental responsibility, while enhancing local pride of place.

By investigating the medieval epistemology of the monstrous, the thesis reveals the demonstrative power of monsters, underscoring their relevance as anti-rational critiques. Medieval monsters violate rational categorization by exhibiting hybridism, unexpected scales and metamorphosis; by challenging conventional boundaries, they provoke critical reconsideration of the human identity. Monstrous architecture is shown to have analogous abilities; the tectonics of construction are interpreted as demonstrations, and architectural details prompt questions concerning the relationship between the built environment and human corporeality. The thesis then examines the monstrous corporeality of the grotesque body, arguing that the architecture of remediation benefits from critical consideration of this concept. Its monstrous corporeality contrasts sharply with the immutable completion of neoclassical ideals; the architecture of remediation furthers its ability to demonstrate the process of healing by drawing inspiration from the grotesque body's dynamic blurring of interiority and exteriority. 
The study of monstrous corporeality also addresses pre-modern European attitudes towards menstruation, which imbued the biological process with a variety of often-contradictory meanings. Having been popularly perceived as a means of flushing out impurities, menstruation was also interpreted as a demonstration of health and fertility; in the design, these themes manifest themselves architecturally as the water's flow through the recreation centre and surrounding landscape. Filtering visibly through purifying pools and channels, the water demonstrates the act of remediation, which itself carries connotations of purification and rebirth. Many of the other meanings attributed to menstruation cast the process in a less favourable light, emphasising the perceived toxicity of menstrual fluid.

In narratives describing the artificial creation of life, the creations of alchemists and mad scientists are monstrous due to their synthetic origins. Like medieval monsters, these creations are shown to function as anti-rational critiques; they demonstrate the dangers of an uncritical faith in progress and the perils of technology unguided by ethics. The thesis further develops the theme of monstrosity through an analysis of the most significant of these narratives: Mary Shelley's Frankenstein: A Modern Prometheus. In addition to demonstrating public anxieties concerning the increasing pervasiveness of technology, the narrative is also found to function as an unsettling critique of humanity. The thesis emphasises the theme of collage, which is evident in the story's layered narrative structure, its conflicted characters and most especially in the monster's assembled corporeality. Incorporating ideas of hybridism and metamorphosis, the theme of collage informs the design of the recreational centre as well as its architectural representation. 
Insights gained from relating the discourse of monstrosity to the architecture of brownfield remediation, and the specific case of Landschaft Park Duisberg Nord, are also used to inform the design. By imbuing the intervention with a demonstrative capacity, the act of remediation is intended to extend beyond the physical limits of the site, encouraging public reconsideration of technology's role in the post-industrial city. The representations of the proposal are also informed by the idea of monstrosity; through collage they demonstrate the monstrous theme of metamorphosis.

When informing the design of remediation architecture, monstrosity enhances the intervention's ability to convey the process of healing: it becomes a demonstration. While this thesis emphasises the theme of metamorphosis due to its relevance to the redevelopment of brownfields, other monstrous themes, such as hybridism and unexpected scale, also merit exploration. Designs beyond brownfield remediation can also be informed by the concept of monstrosity; as anti-rational critiques, monsters find renewed relevance in post-modern society. 


\section{BIBLIOGRAPHY}

Abley, Ian and Heartfield, James. Sustaining Architecture in the Anti-Machine Age. Chichester, England: Wiley-Academy, 2001.

Bildhauer, Bettina and Mills, Robert, "Introduction: Conceptualizing the Monstrous" The Monstrous Middle Ages. Bettina Bildhauer and Robert Mills, eds. Toronto: University of Toronto Press, 2003.

Brooks, Peter. "Godlike Science/Unhallowed Arts: Language and Monstrosity in Frankenstein" New Literary History, Vol. 9, No. 3, Rhetoric I: Rhetorical Analysis. (Spring, 1978), pp. 591-605.

Canada Mortgage and Housing Corporation. "Brownfield Redevelopment for Housing: Case Studies" Research Highlight. August, 2006.

Cohen, Jeffrey Jerome. Of Giants: Sex, Monsters, and the Middle Ages. Minneapolis, Minnesota: University of Minnesota Press, 1999.

Crawford, Patricia. "Attitudes to Menstruation in Seventeenth-Century England." Past and Present, No. 91. (May, 1981), pp. 47-73.

De Sousa, Christopher. Brownfields Redevelopment and the Quest for Sustainability. Amsterdam: Elsevier 2007.

Design Centre, The New Montreal. translated by Käthe Roth from the catalogue for the exhibition Le Nouveau Montréal, Projects urbains marquants dans le Vieux- Montréal, University of Montreal, January 25 to February 25, 2001.

Douglas, Mary. Purity and danger: an analysis of concepts of pollution and taboo. London: Routledge \& K. Paul, 1966.

Dzantor, E. Kudjo, and Beauchamp, Robert G. "Phytoremediation, Part 1: Fundamental Basis for the Use of Plants in Remediation of Organic and Metal Contamination" Environmental Practice No. 4, (2002), pp. 77-87.

EPA (United States Environmental Protection Agency). Introduction to Phytoremediation. EPA/600/R-99/107, February 2002.

Frascari, Marco. Monsters of Architecture: Anthropomorphism in Archtectural Theory. Baltimore, MD: Rowman and Littlefield, 1991.

Frayling, Christopher. Mad, Bad and Dangerous? The Scientist and the Cinema. London: Reaktion Books, 2005. 
Gans, Deborah. "The Sky Above and the Ground Below Emscher" Architectural Design "Extreme Sites: the 'Greening' Brownfield" Deborah Gans and Claire Weisz, eds. Vol. 74, No. 2 (March/April 2004) pp 50-54.

Gauzin-Muller, Dominique. Sustainable Architecture and Urbanism: Concepts, Technologies, Examples. Boston: Birkhauser, 2002.

Glassheim, Eagle. "Ethnic Cleansing, Communism, and Environmental Devastation in Czechoslovakia's Borderlands, 1945-1989" The Journal of Modern History. 78 (March 2006), p65-92.

Graham, Elaine L. Representations of the post/human: Monsters, aliens and others in popular culture. New Brunswick, NJ: Rutgers University Press, 2002.

Gravenor, Kristian. "Last Irishman standing: How bureaucracy leveled the once Shamrockerriffic Griffintown " Montreal Mirror Archives. [http://www.montrealmirror.com/ARCHIVES/2004/031104/news2.html] Mar 1117.2004: INSIDE - COVER,

Hardy, Hugh. "The Romance of Abandonment: Industrial Parks" Places 17 no3 Fall 2005.

Haynes, Rosalynn D. From Faust to Strangelove: Representations of the Scientist in Western Literature. Baltimore: Johns Hopkins University Press, 1994.

Helman, Cecil. 'Dr. Frankenstein and the Industrial Body: Reflections on 'Spare Part' Surgery" Anthropology Today, Vol. 4, No. 3. (Jun., 1988), pp. 14-16.

Hewitt, Mark and Haga, Susanna. City Fights: debates on urban sustainability. London: James \& James, 2001.

Jelacic, Matthew. "Arch Intimacy" Architectural Design "Extreme Sites: the 'Greening' Brownfield” Deborah Gans and Claire Weisz, eds. Vol. 74, No. 2 (March/April 2004) pp. 61-63.

Johnston, George Barnett. "Architecture and Alchemy" Journal of Architectural Education (1984-88), Vol. 41, No.2. (Winter, 1988), pp. 10-20.

Kronenburg, Robert. Spirit of the Machine Age: Technology as an Inspiration in Architectural Design. Chichester, England: Wiley-Academy, 2001.

Lasansky, D. Medina and McLaren, Brian, eds. Architecture and Tourism: perception, performance and place. New York: Berg, 2004.

Leitz, Robert C. and Cope, Kevin L. Imagining the Sciences: Expressions of New Knowledge in the "Long” Eighteenth Century. New York: AMS Press, 2004. 
Ligo, Larry L. The Concept of Function in Twentieth-Century Architectural Criticism. Ann Arbor, MI: UMI Research Press, 1984.

Lortie, André, ed. The 60's: Montreal thinks big. Montreal: Canadian Centre for Architecture, 2004.

Kirkwood, Niall, ed. Manufactured Sites. New York: Spon Press, 2001

McCord Museum. "The Victoria Bridge: Eighth Wonder of the Modern World" http://www.mccord-museum.qc.ca/en/keys/virtualexhibits/victoriabridge/

Montréal, Service des parcs, des jardins et des espaces verts. LACHINE CANAL INTERACTIVE CD-ROM. Ville de Montréal, 2000.

Newman, William. "Technology and Alchemical Debate in the Late Middle Ages" Isis Vol. 80, No.3. (Sep., 1989), pp. 423-335.

Paul, Darel E. "World cities as hegemonic projects: the politics of global imagineering in Montreal" Political Geography 23 (2004), pp.571-596.

Porteus, Colin. The New eco-Architecture. New York: Spon Press, 2002.

Schelde, Per. Androids, Humanoids and other Science Fiction Monsters. New York: New York University Press, 1993.

Shelley, Mary. Frankenstein. New York: Airmont Books, 1963.

Sherwin, Paul. "Frankenstein: Creation as Catastrophe" PMLA, Vol. 96, No. 5. (Oct., 1981), pp. 883-903.

Sijpkes, Peter. "The Four Lives of Point St. Charles" Grassroots Greystones \& Glass Towers. Bryan Demchinsky, ed. Montréal: Véhicule Press, 1989. pp. 176-190.

Steinglass, Matt. "The Machine in the Garden" METROPOISMAG.COM. http://www.metropolismag.com/cda/

Stilgenbauer, Judith. "Landschaftspark Duisburg Nord - Duisburg, Germany" Places 17 no3 Fall 2005.

Toumey, Christopher P. "The Moral Character of Mad Scientists: A Cultural Critique of Science" Science, Technology, \& Human Values, Vol. 17, No. 4 (Autumn, 1992), pp. 411-437.

Verner, Lisa. The Epistemology of the Monstrous in the Middle Ages. New York: Routledge, 2005. 
Zloniky Peter, "Strategies for Extreme Conditions: the Emscher Park International Building Exhibition" Architectural Design "Extreme Sites: the 'Greening' Brownfield" Deborah Gans and Claire Weisz, eds. Vol. 74, No. 2 (March/April 2004) pp 54-60. 